\title{
DNA methylation, a hand behind neurodegenerative diseases
}

\section{Haoyang Lu ${ }^{\dagger}$, Xinzhou Liu ${ }^{\dagger}$, Yulin Deng and Hong Qing *}

School of Life Science, Beijing Institute of Technology, Beijing, China

Edited by:

Isidro Ferrer, University of

Barcelona, Spain

Reviewed by:

Andrea Fuso, Sapienza University of Rome, Italy

Jose V. Sanchez-Mut, Bellvitge

Biomedical Research Institute, Spain

*Correspondence:

Hong Qing, School of Life Science,

Beijing Institute of Technology,

5 South Zhongguancun Street,

Haidian District, Beijing 100081,

China

e-mail: hqing@bit.edu.cn

tThese authors have contributed

equally to this work.
Epigenetic alterations represent a sort of functional modifications related to the genome that are not responsible for changes in the nucleotide sequence. DNA methylation is one of such epigenetic modifications that have been studied intensively for the past several decades. The transfer of a methyl group to the 5 position of a cytosine is the key feature of DNA methylation. A simple change as such can be caused by a variety of factors, which can be the cause of many serious diseases including several neurodegenerative diseases. In this review, we have reviewed and summarized recent progress regarding DNA methylation in four major neurodegenerative diseases: Alzheimer's disease (AD), Parkinson's disease (PD), Huntington's disease (HD), and amyotrophic lateral sclerosis (ALS). The studies of these four major neurodegenerative diseases conclude the strong suggestion of the important role DNA methylation plays in these diseases. However, each of these diseases has not yet been understood completely as details in some areas remain unclear, and will be investigated in future studies. We hope this review can provide new insights into the understanding of neurodegenerative diseases from the epigenetic perspective.

Keywords: DNA methylation, Alzheimer's disease, Parkinson's disease, Huntington's disease, amyotrophic lateral sclerosis

\section{INTRODUCTION}

Epigenetic refers to the study of mitotically or meiotically heritable changes in gene functions that cannot be explained by changes in DNA sequence. In most cases, it acts as the heritable regulation of DNA transcription by DNA methylation, histone modification and expression of noncoding RNAs. Since R. D. Hotchkiss (Hotchkiss, 1948) discovered that DNA can be methylated at the 5-position of cytosine in 1948, the mysterious veil on epigenetics has been gradually lifted. A study of in discordant twins pointed out that epigenetics can make a difference, even in a pair of monozygotic twins (Fraga et al., 2005). Fraga et al. uncovered that even if sharing a common genotype, twins still showed different penetrance of various diseases such as neurological disorders. Among epigenetic mechanisms, DNA methylation is a crucial epigenetic marker that has been most widely studied. Alterations of DNA methylation are involved in many human diseases including cancer and neurological disorders.

Neurodegenerative diseases are one kind of neurological diseases featuring the progressive loss and even final death of neurons. The specific causes and pathological mechanisms of neurodegenerative diseases have not been completely understood. Recently, a large amount of evidence have emerged to show a shared non-Mendelian property between DNA methylation and neurodegenerative diseases, a connection that has peaked research interest for over two decades.

The main purpose of this review is to provide an overview on the involvement of DNA methylation in the pathology of neurodegenerative disease. We will begin by outlining the concept of DNA methylation, then focus intensively on recent progress made in the study of DNA methylation in four major neurodegenerative diseases: Alzheimer's disease (AD), Parkinson's disease (PD), Huntington's disease (HD), and amyotrophic lateral sclerosis (ALS). We will discuss in depth the relationship between DNA methylation and neurodegenerative diseases, as well as the causal and consequential effect of DNA methylation in these diseases.

\section{THE PRINCIPLE OF DNA METHYLATION}

As the most widely characterized epigenetic modification, DNA methylation in eukaryotes is found nearly exclusively at cytosine residues. A methyl group is added at the 5-position of cytosine before a guanine and gene silencing is frequently associated with this modification. This dinucleotide unit is always written as $\mathrm{CpG}$, representing a combination of a cytosine, the following guanine and a phosphate group between them. Regions with high concentration of CpGs are called CpG islands, which usually locate in promoter region of genes, a place where most CpGs in the human genome exist. Cytosines are usually not methylated in $\mathrm{CpG}$ islands, but for some particular functions, such as $\mathrm{X}$ chromosome inactivation, methylation of $\mathrm{CpG}$ islands is also required. On the other hand, predominantly located in repetitive or centromeric sequences, $\mathrm{CpGs}$ outside $\mathrm{CpG}$ islands are usually methylated (Reik et al., 2001; Bird, 2002). Data showed that unmethylated regions of the genome are protected from DNA methylation by a combination of factors involving very high $\mathrm{CpG}$ densities and histone modifications, while the remaining bulk of the genome is methylated as the default state (Edwards et al., 2010). CpG methylation within promoter and intragenic sites have been extensively studied and recent interest have also arisen regarding non-CpG methylation, which refers to the methylation 
that occurs at cytosines of non-CpG dinucleotides, such as CA, $\mathrm{CT}$, or CC. While CpG methylation can occur whenever gene silencing is needed during the life span of a cell, non-CpG methylation is dominantly present in embryonic stem cells (Haines et al., 2001; Dodge et al., 2002; Lister et al., 2009) as well as in neural development (Lister et al., 2013).

More specifically, 5-methylcytosine $(5 \mathrm{mC})$ is produced by transferring a methyl group from an S-adenosyl-L-methionine (SAM) to the cytosine with the help of DNA methyltransferases (DNMTs) (Figure 1). Five kinds of proteins-DNMT1, DNMT2, DNMT3a, DNMT3b, and DNMT3L are major members of DNMT family (Bestor, 2000). The functions of DNMT in DNA methylation can be divided into maintenance methylation and de novo methylation. DNMT1 is involved in maintenance methylation, which refers to the process of copying DNA methylation profiles to the daughter strands during DNA replication. DNMT3a and DNMT3b are de novo methyltransferases that establish DNA methylation patterns in early development. DNMT3L has no catalytic activity but can assist the de novo methyltransferases by improving their ability of binding to DNA and stimulating their activity. Instead of methylating DNA, DNMT2 was shown to methylate the anticodon loop of aspartic acide transfer RNA at cytosine-38 (Goll et al., 2006). Recognizing and binding of methyltransferases to 5-methylcytosines requires methyl-CpG binding domain (MBD) proteins, which are $\mathrm{MeCP} 2$, MBD1, MBD2, MBD3, and MBD4 in mammals (Fatemi and Wade, 2006). In addition to $5 \mathrm{mC}$, there exists another kind of methylated cytosine, 5-hydroxymethylcytosine ( $5 \mathrm{hmC})$, which is consequence of the oxidation of $5 \mathrm{mC}$ that is catalyzed by the teneleven translocation (TET) proteins. In turn, $5 \mathrm{hmC}$ also can be deaminated to $5 \mathrm{mC}$ via the mediation of AID/APOBEC family proteins. $5 \mathrm{hmC}$ in mammalian DNA was first described in the early 1970s (Penn et al., 1972), however, it has been poorly studied until recently when studies found that $5 \mathrm{hmC}$ is present in mouse neurons as well as in embryonic stem cells (Kriaucionis and Heintz, 2009; Tahiliani et al., 2009). Since then, it has been substantiated that $5 \mathrm{hmC}$ can influence the regulation of gene expression, and the conversion of $5 \mathrm{mC}$ to $5 \mathrm{hmC}$ may contribute to DNA demethylation that, in most cases, associates with gene activation (Bhutani et al., 2011; Guo et al., 2011a).

DNA methylation works in harmony with histone acetylation to control memory formation and synaptic plasticity (Miller et al., 2008), and it also has a possible impact on genetic and neuronal function affecting behaviors (Day and Sweatt, 2010). Besides, the connection among DNA methylation, chromatin structure and gene silencing has been extensively studied for many years, and the gene silencing is thought to be an epigenetic intervention on neurodegenerative diseases like AD (Scarpa et al., 2006). Therefore, we can believe that there is a very strong potential link between DNA methylation and neurodegenerative diseases as we will talk about below.

\section{DNA METHYLATION AND ALZHEIMER's DISEASE INTRODUCTION TO ALZHEIMER'S DISEASE}

$\mathrm{AD}$ is the most common form of dementia, which brings acute suffering to its patients. Eleven percent of people age 65 or older and $32 \%$ of people age 85 or older are afflicted by this disease. The general symptom pattern begins with the gradually worsening of ability to remember new information. The patient's cognitive and functional abilities decline as the disease progresses. Extracellular neuritic plaques, intracellular neurofibrillary tangles and neuronal loss are the main pathological hallmarks in $\mathrm{AD}$ brains. $\mathrm{AD}$ is ultimately fatal and has become the sixth leading cause of death in the United States (Thies et al., 2013).

The cause of AD is still unclear. Numerous genetic and environmental risk factors are involved in the etiology and pathogenesis of $\mathrm{AD}$, including alterations in the expression of thousands of genes, amyloid $\beta$-peptide (A $\beta$ ) deposition, tau hyperphosphorylation, inflammation, oxidative stress, energy metabolism, and aberrant re-entry into the cell cycle/apoptosis. It's worth noting that when $\mathrm{A} \beta$-inducing mutations are absent, these molecular and genetic factors do not have absolute penetrance in causing the disorder (Mastroeni et al., 2011).

Two dominant hypotheses to explain the disease are $A \beta$ hypothesis and tau hypothesis. Redundant $A \beta$ is considered a main contributor to the dysfunction and degeneration of neurons that occurs in $\mathrm{AD} . \mathrm{A} \beta$, a 38-43 amino acid peptide, is gained from sequential $\beta$ - and $\gamma$-secretase cleavages of amyloid- $\beta$ precursor protein (APP). When the cleavage site lies within the $A \beta$ sequence, another APP processing enzyme, $\alpha$-secretase, precludes $\mathrm{A} \beta$ formation. Beta-site APP cleaving enzyme 1 (BACE1) is the major $\beta$-secretase in the brain. $\gamma$-Secretase consists a minimum 4 proteins: presenilin 1 (PS1) or presenilin 2 (PS2), nicastrin (Nct), presenilin enhancer 2 (Pen2), and anterior pharynx defective 1 (Aph-1) (Chow et al., 2010). Another hypothesis, the tau hypothesis, is based on the hyperphosphorylation of tau in patients with AD. How phosphorylation influences tau function is only poorly understood, but it negatively regulates the binding of tau to microtubules. Hence, functions of tau such as microtubule stabilization and the regulation of axonal transport may be compromised, possibly contributing to disease. Moreover, interactive enhancements between $\mathrm{A} \beta$ and tau were also proposed recently (Ittner and Gotz, 2011).

$\mathrm{AD}$ can be generally categorized into two divisions. Less than $2 \%$ of $\mathrm{AD}$ cases are early-onset Alzheimer's disease (EOAD), which onsets prior to age 60 with genetic mutations in APP, presenilin 1, or presenilin 2 genes. Mutations in these genes dysregulate the APP pathway and directly lead to A $\beta$ plaque accumulation, a major pathological hallmark of $\mathrm{AD}$. Other cases which are sporadic and manifest symptoms after age 60, are termed lateonset Alzheimer's disease (LOAD). At least one apolipoprotein 4 allele (APOE-4) is found in approximately $50-65 \%$ of LOAD cases, while the global population prevalence of the allele is only approximately 20-25\% (van der Flier et al, 2011).

\section{DNA METHYLATION MODIFICATION EVIDENCE IN AD}

DNA methylation modifications related to $\mathrm{AD}$ can be divided into two groups: global DNA methylation modifications and gene-specific DNA methylation modifications. Global DNA hypomethylation and specific gene hypermethylation are the overall phenomenon among studied $\mathrm{AD}$ cases.

\section{Global methylation modification and AD}

Most studies support the view that on the whole-genome scale, the DNA methylation level in $\mathrm{AD}$ cases is lower than in comparison with normal individuals. Direct evidence came from 


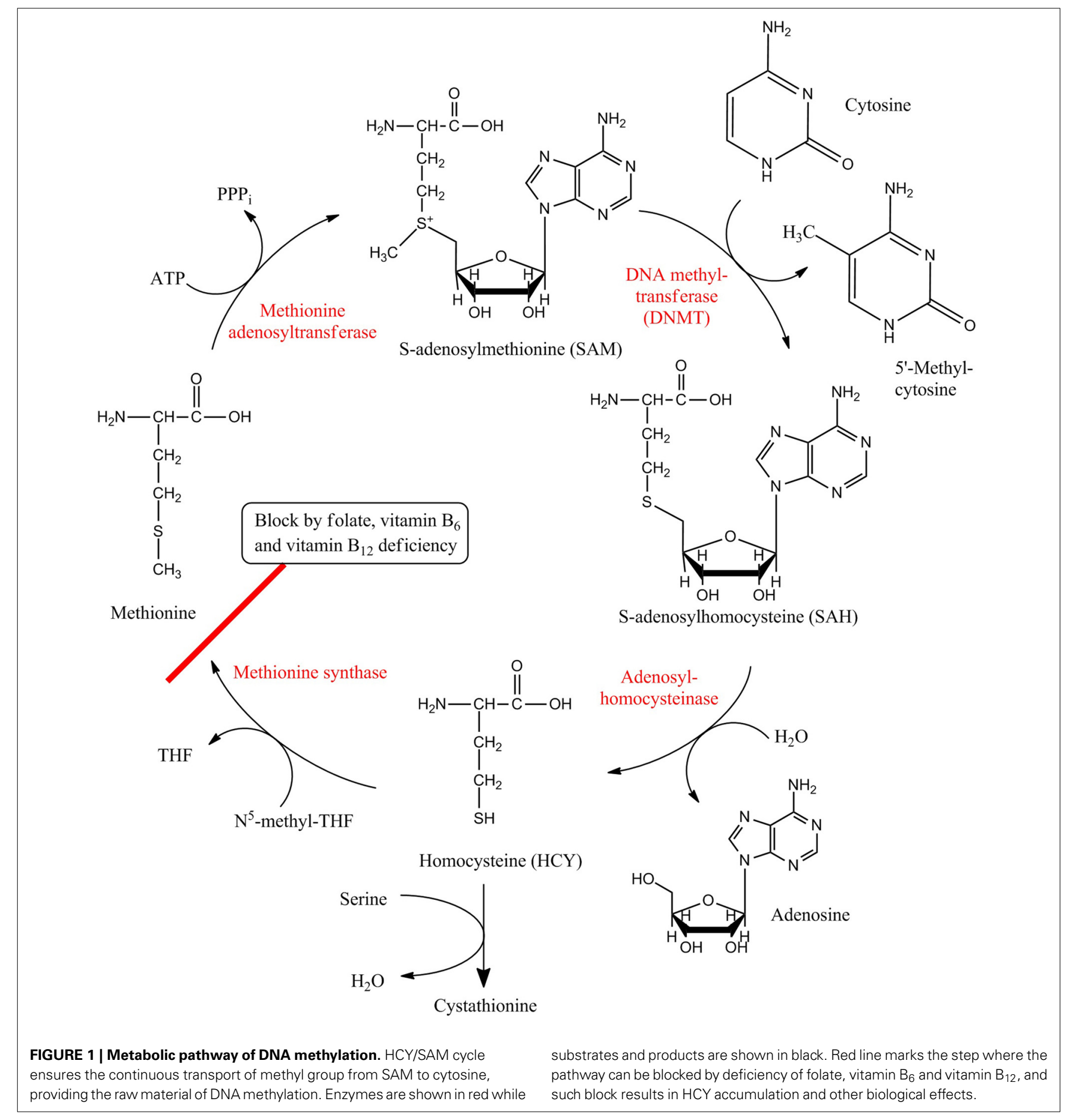

studies in monozygotic twins. A postmortem study of rare sets of monozygotic twins discordant for $\mathrm{AD}$ reported significantly reduced levels of DNA methylation in temporal neocortex neuronal nuclei of the $\mathrm{AD}$ twin, which provided the potential for $\mathrm{AD}$ discordancy in spite of genetic similarities. With specific markers, decrement in DNA methylation was observed in AD reflected among neurons, reactive astrocytes, and microglia (Mastroeni et al., 2009). Research also recognized a dramatic decrease in
$\mathrm{AD}$ patients of far-going epigenetic markers and regulators in neurons from control entorhinal cortex layer II, consistent with the high vulnerability of this brain region to $\mathrm{AD}$ pathology. The result indicates that global DNA and RNA methylation status are significantly diminished in $\mathrm{AD}$ in this region (Mastroeni et al., 2010). This trend of global hypomethylation was further confirmed in a more recent and direct study, in which decrements of $5 \mathrm{mC}$ and $5 \mathrm{hmC}$ were shown in $\mathrm{AD}$ patients' hippocampus by 
a quantitative immunohistochemical method (Chouliaras et al., 2013). A similar result was also shown in a cell line. Using the AD model cell line H4-sw, which harbors the Swedish mutation and produces high levels of the toxic form $A \beta$, global methylation status were analyzed. Among the total 6296 differentially methylated CpG sites, 23\% were shown to be hypermethylated while others were hypomethylated (Sung et al., 2011).

However, such a conclusion is not supported by all the evidence. For instance, a postmortem human frontal cortex genome-wide DNA methylation study also showed general and mild discordant DNA methylation in LOAD-diseased tissue independent of the age factor, while both hypomethylation and hypermethylation were found (Bakulski et al., 2012). Moreover, another postmortem human frontal cortex study showed a trend of global DNA hypermethylation in AD cases (Rao et al., 2012). It is noteworthy that DNA hypomethylation tendency in AD is mainly supported by immunoassays, but the opposite tendency has been observed through bisulfite treatment, which is a direct interrogation of DNA.

\section{Gene specific DNA methylation modification and AD}

Researchers have also traced the methylation modification of a number of specific genes, which are believed to be related to AD. Such studies usually concentrate on the gene promoter region, in which DNA methylation regulates the expression of genes. We will divide these genes into six sections and introduce findings in each section.

A $\beta$-generation-related genes. APP, PS1, and BACE1 play crucial roles in the generation of $A \beta$. Therefore, the promoter regions of their genes have been studied in many different researches.

Recent results overall suggest that there is no correlation between APP methylation modification and AD. A large-scale postmortem study involving frontal cortex and hippocampus found no difference in APP gene promoter region methylation among all stages of $\mathrm{AD}$ patients and healthy controls. The preservation of DNA methylation status in postmortem brain samples was also confirmed (Barrachina and Ferrer, 2009). Another postmortem study focusing on the cortex and cerebel observed no methylated $\mathrm{CpG}$ in APP promoter regions in any familial AD patients and their healthy comparisons (Brohede et al., 2010). However, a study in SH-SY5Y cell lines indicated that the promoter of $A P P$ is capable to be hypomethylated (Guo et al., 2011b).

The situation of PSEN1 (the gene encoding PS1) seems more apparent, since almost every study in this field reports PSEN1 promoter hypomethylation and the resulting overexpression of PSEN1 as factors leading to AD. Firstly, studies in neuroblastoma cell lines (Fuso et al., 2005) and mouse (Fuso et al., 2008, 2011b) showed that PSEN1 can be overexpressed through DNA hypomethylation. Further investigations in mouse ruled out the possibility that hypomethylation of PSEN1 promoter is the consequence of amyloid production (Fuso et al., 2012a). Finally, similar hypomethylation was observed in postmortem study (Wang et al., 2008). However, it should be noted that almost all papers reporting PSEN1 hypomethylation in $\mathrm{AD}$ came from the same laboratory, and these results need to be validated by independent laboratories.
It has also been reported that BACE1 expression can be upregulated via demethylation of at least two CpG sites at position +298 and +351 in the $5^{\prime}$-untranslated region in $B V-2$ microglial cells (Byun et al., 2012).

A $\beta$-degradation-related genes. A $\beta$ peptides are proteolytically degraded within the brain mainly by neprilysin (NEP) (Iwata et al., 2000) and insulin-degrading enzyme (IDE, insulysin) (Kurochkin and Goto, 1994). The endolytic degradation of A $\beta$ peptides within microglia by NEP and related enzymes is significantly enhanced by apolipoprotein E (ApoE). Similarly, A $\beta$ extracellular degradation by IDE is facilitated by ApoE (Jiang et al., 2008). There are three major isoforms of ApoE: ApoE2, ApoE3, and ApoE4. Among them, ApoE3 is the most common isoform in the population, while ApoE4 has been shown to confer dramatically increased risk for LOAD (Roses et al., 1995).

It has been reported that $\mathrm{A} \beta$ causes $N E P$ promoter region hypermethylation, which consequently suppresses NEP's expression in mRNA and protein levels, reduces the $A \beta$ clearance and probably elevates $A \beta$ accumulation. This could be part of a vicious cycle which plays a role in the pathophysiology of AD (Chen et al., 2009). Sortilin-related receptor (SORL1, also known as SORLA, SORLA1, or LR11) is a neuronal ApoE receptor. Its connection with $\mathrm{AD}$ is based on its reduction in $\mathrm{AD}$ brains and its ability to lower $A \beta$ levels (Offe et al., 2006). The SORL1 gene showed differences in its expression among peripheral blood leukocytes, and it may act as a marker of aging in this tissue. It has been shown that SORL1 promoter DNA methylation could serve as one of the mechanisms in charge of the differences in expression observed between blood and brain for both healthy elders and $\mathrm{AD}$ patients groups (Furuya et al., 2012a).

Tau-related genes. Activity and expression level of glycogen synthase kinase $3 \beta$ (GSK3 $\beta$ ), the major kinase that phosphorylates tau in the brain, are increased in AD brains (Nicolia et al., 2010).

A study in human neuroblastoma SK-N-BE cell line and TgCRND8 mouse showed that GSK3 $\beta$ gene's promoters can be hypomethylated by inhibiting methylation activity through $\mathrm{B}$ vitamin deficiency and such hypomethylation results in the overexpression of GSK3 $\beta$ (Nicolia et al., 2010). It was also reported that inhibition of GSK3 $\beta$ reduces the expression of DNMT3A and causes hypomethylation of related genes in mouse embryonic stem cells (Popkie et al., 2010).

Genes involved in metabolic pathways. Another finding is that rare haplotypes may be associated with the risk of AD through a possible modulation of the methylation of the ornithine transcarbamylase (OTC) promoter. In spite of being mostly speculative, it might suggest a deregulation of urea cycle in $\mathrm{AD}$ (Bensemain et al., 2009).

Ribosomal DNA (rDNA). Ribosomal deficits are verified in mild cognitive impairment (MCI), which often represents an early stage $\mathrm{AD}$ as well as the potential of advanced $\mathrm{AD}$ (Ding et al., 2005). Although an early study didn't detect any differential methylation pattern of rDNA genes in total peripheral blood cells in elderly and AD subjects (Speranca et al., 2008), it was reported later that the rDNA promoter become hypermethylated 
in studied $\mathrm{AD}$ cerebrocortical samples, suggesting that $\mathrm{rDNA}$ hypermethylation could be implicated in AD (Pietrzak et al., 2011).

Other genes. The complexity of $\mathrm{AD}$ and epigenetics leads to an endless stream of research. One study suggested that behavioral and psychological symptoms in dementia patients may be caused by the methylation disturbance of circadian gene (Liu et al., 2008). In addition, DNA methylation status of repetitive elements long interspersed element-1 (LINE-1) was shown to be increased in $\mathrm{AD}$ patients compared with healthy volunteers (Bollati et al., 2011). Moreover, various potential functions of neuroglobin (NGB) have been exhibited and found to be able to reduce the severity of stroke and $\mathrm{AD}$ (Khan et al., 2007). A 5-aza-2'-deoxycytidine (a methyltransferase inhibitor) treatment analysis indicated that DNA methylation/demethylation may be involved in regulating NGB tissue-specific expression (Zhang et al., 2011). Another separate research implies that long telomeres with hypomethylation tend to shorten faster, while cells bearing short telomeres with hypomethylation tend to enter into a senescent state under elevated $\mathrm{OS}$ stress in $\mathrm{AD}$ more easily. It has been validated that this trend can be reversed by vitamin E (Guan et al., 2012). Rao et al. reported hypomethylated cyclooxygenase-2 (COX-2) (one of the arachidonic acid (AA) cascade markers) and brain-derived neurotrophic factor (BDNF) promoter regions in $\mathrm{AD}$ brain, while the promoter region of cAMP response element-binding protein $(C R E B)$, which regulates the transcription of $B D N F$, was shown to be hypermethylated. Their study also found a significant increase in DNA methylation at the promoter region of synaptophysin $(S Y P)$ and decreased methylation of the NF-kB promoter CpG region in the $\mathrm{AD}$ (Rao et al., 2012). S100A2 is a member of the S100 family of calcium binding proteins while SORBS3 encodes a cell adhesion molecule expressed in neurons and glia. The decrement of S100A2 and increment in SORBS3 CpG methylation in AD brains were reported from a postmortem study (Siegmund et al., 2007).

Some other genes involved in $\mathrm{AD}$ were also investigated, but no DNA methylation differences have been found in these genes. These genes include synaptosomal-associated protein 25 (SNAP25) (Furuya et al., 2012b), SIRT3, SMARCA5, CDH1 (Silva et al., 2008), $2^{\prime}, 3^{\prime}$-cyclic-nucleotide $3^{\prime}$-phosphodiesterase (CNP), and dihydropyrimidinase-like 2 (DPYSL2) (Silva et al., 2013).

\section{DNA METHYLATION AND PARKINSON'S DISEASE INTRODUCTION TO PARKINSON'S DISEASE}

$\mathrm{PD}$ is the second most common neurodegenerative disorder after AD. According to the PD Foundation, about 1 million people in the United States and more than 4 million people worldwide are affected with this disease. The prevalence of PD in industrialized countries is generally estimated at about $1-2 \%$ of population over 60 years of age, and increases to $3-5 \%$ in people above 85 years old. This neurodegenerative disorder is characterized by the progressive loss of substantia nigra dopaminergic neurons and striatal projections, causing the typical symptomatology: muscle rigidity, bradykinesia, tremor, and postural instability (de Lau and Breteler, 2006).
Although more than $90 \%$ of the cases can be interpreted as sporadic $\mathrm{PD}$, the greatest insights into PD etiology have come from the study of familial forms. In recent years, mutations in six genes have been identified as causes of PD: SNCA (which encodes $\alpha$-synuclein), PARK2 (parkin), PINK1 (PTEN-induced kinase protein 1), UCHL1 (ubiquitin carboxyl-terminal hydrolase isozyme L1), DJ1 (protein DJ-1), and LRRK2 (leucine-rich repeat serine/threonine-protein kinase 2). The hallmark neuropathological sign of PD is the presence of fibrillar aggregates of misfolded $\alpha$-synuclein called Lewy bodies, which accumulate in the same sites where neuronal loss is found (Urdinguio et al., 2009).

Although PD is less studied than $\mathrm{AD}$ in terms of the relation to epigenetics, this section aimed to review the interrelation of PD and DNA methylation is organized into two parts. First part is exploring what genetic factors of $\mathrm{PD}$ pathogenesis might be affected by DNA methylation, and the other one is aimed to showing how environmental factors could get involved in the alteration of DNA methylation leading to PD.

\section{GENETIC FACTORS, DNA METHYLATION AND PD DNA methylation regulation of $\alpha$-synuclein}

Considering that $\alpha$-synuclein makes a major contribution to the formation of Lewy bodies and even to the entire pathogenesis of $\mathrm{PD}$, we start from discussion on impact DNA methylation has on $\alpha$-synuclein.

An earlier study revealed that the DNA methylation pattern within the $\alpha$-synuclein (SNCA) gene promoter region was altered in the blood samples of patients with alcoholism, which was significantly associated with their increased homocysteine levels (Bonsch et al., 2005). This is the first study, to the best of our knowledge, to show a correlation between DNA methylation and $\alpha$-synuclein in certain syndromes. Later on, it has been reported that the methylation of human SNCA intron 1 decreased gene expression while inhibition of DNA methylation activated its expression in the brains of PD patient (Jowaed et al., 2010), which further strengthens the link. Although analysis of postmortem brain did not reveal regional specific methylation differences in the putamen and anterior cingulate between PD and healthy individuals, methylation was found specifically and significantly reduced in the substantia nigra of $\mathrm{PD}$ patients (Matsumoto et al., 2010). In addition, single CpG analysis reflected fluctuating methylation levels at different locations in various brain regions and LBD stages, even if the overall methylation levels in the promoter and intron 1 of $\alpha$-synuclein gene were reported to be similarly low both in Lewy body disease (LBD) patients and controls(de Boni et al., 2011). These results suggest a potential role of DNA methylation in $\alpha$-synuclein neuropathogenesis.

Unfortunately, in the blood cell sample of a PD patient with heterozygous SNCA A53T mutation, $\alpha$-synuclein expression was found to be monoallelic because of epigenetic silencing of the mutated allele through histone modification instead of DNA methylation (Voutsinas et al., 2010). Rather than altering DNA methylation, $\alpha$-synuclein negatively regulated PKC-delta expression in human dopaminergic neurons by reducing histone modification (Jin et al., 2011). Moreover, no differential methylation of SNCA was observed in white blood cell DNA of PD patients 
compared to the neurologically normal controls (Richter et al., 2012).

Nonetheless, the interaction of DNMT and $\alpha$-synuclein has also been tested. Reduction of nuclear DNMT1 levels was observed in postmortem brain samples from PD patients and in the brains of $\alpha$-synuclein transgenic mice, underlying a mechanism in which DNMT1 might be excluded from the nucleus by $\alpha$-synuclein, and the segregation of DNMT1 further resulted in hypomethylated $\mathrm{CpG}$ islands upstream of $\alpha$-synuclein(Desplats et al., 2011).

Overall, these results indicate that there is a good chance that DNA methylation is involved in the regulation of $\alpha$-synuclein gene expression, even if its specific role still remains to be further clarified.

\section{DNA methylation in other genes related to PD}

In addition to $\alpha$-synuclein, several other genes also have been examined to find whether they are associated with PD in a DNA-methylation-regulated way.

Tumor necrosis factor $\alpha$ (TNF- $\alpha)$ is a critical inflammatory cytokine and increased TNF- $\alpha$ is associated with dopaminergic cell death in PD. It has been suggested that a lesser extent of methylation of the TNF- $\alpha$ promoter in human substantia nigra cells could uphold the increased vulnerability of dopaminergic neurons to TNF- $\alpha$ regulated inflammatory reactions (Pieper et al., 2008). Because TNF- $\alpha$ overexpression induces apoptosis in neuronal cells and TNF- $\alpha$ levels were rather high in the cerebrospinal fluid of PD patients (Mogi et al., 1996), we can speculate that DNA methylation might be the reason for such overexpression of TNF- $\alpha$. As is well known, the parkin gene plays a relatively important part in the emergence and development of PD. The methylation levels of the parkin gene promoters were analyzed in samples from PD patients heterozygous for parkin mutations, PD patients without parkin mutations, and normal controls, however, no significant difference was observed among the three groups, indicating that parkin promoter methylation alone is unlikely to impact the pathogenesis and development of PD (Cai et al., 2011). Ubiquitin c-terminal hydrolase L1 is a member of one subfamily of deubiquinating enzymes that remove ubiquitin from ubiquitinated substrates in the ubiquitin proteasome degradation system. Dysfunction of UCHL-1 has been implicated in the pathogenesis of neurodegenerative disorders, including PD. The UCHL1 promoter was found hypermethylated in diverse types of cancer (Kagara et al., 2008; Yu et al., 2008), however, analysis of UCHL1 promoter in the hippocampus and frontal cortex of PD patients and controls displayed no significant differences in $\mathrm{CpG}$ methylation between these two groups (Barrachina and Ferrer, 2009). A large-scale sequencing analysis of postmortem brain samples identified methylation and expression changes associated with $\mathrm{PD}$ risk variants in PARK16/1q32, GPNMB/7p15, and STX1B/16p11 loci, suggesting that some other PD-related genes could also be epigenetically modified in PD brains (Plagnol et al., 2011).

More recently, it was reported that the expression of clock genes was altered in both PD patients and in animal models of the disease (Cai et al., 2010; Hood et al., 2010). Promoter methylation analysis of seven clock genes in blood samples of PD revealed that most clock gene promoters were short of methylation, suggesting that altered promoter methylation may contribute to the aberrant expression of clock genes in PD (Lin et al., 2012). A genome-wide methylation analysis of PD with quantities DNA methylation levels found reduced methylation of the cytochrome P450 2E1 gene in PD patients' brains compared to the controls, which suggests that epigenetic variants inde-toxifying enzymes, such as cytochrome genes, may add to PD susceptibility (Kaut et al., 2012). Mesodiencephalic dopaminergic (mdDA) neurons, located in the ventral mesodiencephalon, are involved in severely affected neurodegenerative diseases such as PD. Emerging evidence shows that epigenetic mechanisms including DNA methylation play an important role in mdDA development, maturation and maintenance (van Heesbeen et al., 2013). Furthermore, other specific genomic regions were also examined on the methylation level. For example, researchers have found that the number of short telomeres with constant subtelomeric methylation status was smaller in peripheral leukocytes from Japanese PD patients compared to the healthy controls (Maeda et al., 2009). Although, based on the limited number of studies in this field, we cannot come up with a meaningful conclusion from these findings, but at least there might be a bold hypothesis that DNA methylation associates with PD through a variety of genetic pathways.

\section{ENVIRONMENTAL FACTORS AND DNA METHYLATION IN PD}

Environment can significantly affect the risk and progression of neurodegenerative disorders including PD. Here we synthesized published studies focused on the interaction between DNA methylation and environmental factors in PD cases.

Elevated plasma homocysteine levels have been documented in PD individuals (O'Suilleabhain et al., 2004). A further increase in plasma homocysteine levels of blood cell samples was observed in individuals with both PD and the MTHFR C677T mutation (Brattstrom, 2001). PD patients undergoing regular treatment with L-Dopa had higher plasma homocysteine concentrations relative to healthy controls, indicating a possible methylated catabolism of the drug (Blandini et al., 2001). Dietary folate deficiency and elevated homocysteine levels have been found to be harmful to dopaminergic neurons in mouse models of PD (Duan et al., 2002). A recent study found out that hallmarks of neurodegeneration such as APP and $\alpha$-synuclein were related to markers of methylation like SAM and its downstream byproduct, S-Adenosyl-L-homocysteine (SAH) in individuals with PD (Obeid et al., 2009). A higher SAM/SAH ratio, which indicates a higher methylation potential, was linked to better cognitive function. Note that the SAM/SAH ratio is a significant positive predictor of DemTect scores in PD patients and DemTect is a cognitive screening instrument sensitive to the early cognitive symptoms of dementia including $\mathrm{AD}$ and $\mathrm{PD}$ (Kalbe et al., 2004).

Telomeric dysfunction has been discovered to be associated with development of age-related pathologies, and similarly to $\mathrm{AD}$, shortened telomeres were found present in patients with $\mathrm{PD}$ (Guan et al., 2008). Telomere length is epigenetically regulated by DNA methylation, which in turn could be modulated by folate status. In human, telomere length has been reported to be associated with folate status (Paul et al., 2009). Plus, various nutrients also showed potential to influence regulation of telomere length, 
e.g., folate, via its role in epigenetic status of DNA methylation and histone modification (Paul, 2011).

Besides, environmental exposure, including paraquat, is believed to be a risk for PD. Interestingly, a pretreatment of PC12 with 5-aza-2'deoxycytidine, a DNMT inhibitor, sensitizes cells to paraquat exposition. Similar results were obtained using dopaminergic cells and treatments of $\operatorname{MPP}(+)$, 6-hydroxydopamine and rotenone, (Wang et al., 2013) suggesting that DNA methylation might modulate the effect of these toxins and might play a role in PD susceptibility (Kong et al., 2012). These findings underlie a possible mechanism in which environment influences pathology of PD via DNA methylation modification. Nevertheless, since data presented so far are too insufficient to substantiate any hypothesis, further solid findings are very necessary and helpful to arrive at a reliable conclusion.

\section{DNA METHYLATION AND HUNTINGTON'S DISEASE INTRODUCTION TO HUNTINGTON'S DISEASE}

$\mathrm{HD}$, or Huntington's chorea, is the most common genetic cause of chorea in high-income countries, with a prevalence of about one in 10,000 people. This lethal neurodegenerative disease primarily affects the cerebral cortex and the striatum. Initial physical symptoms are chorea, rigidity, and dystonia, and become more apparent as the disorder progresses. Cognitive abilities become gradually impaired, finally leading to dementia (Babenko et al., 2012).

$\mathrm{HD}$ is caused by the expansion of CAG triplet repeats in the HTT gene, which encodes an expanded polyglutamine (polyQ) stretch in the huntingtin (HTT) protein. Normal HTT genes contain CAG repeats no more than 35, and are not associated with the disorder. Incomplete penetrance happens with 36-40 repeats. However, when these repeats reach 41 or more, the disease becomes completely penetrant. The number CAG repeats accounts for $\sim 60 \%$ of the variation in age of onset, and the rest can be explained by modifying genes and environment (Walker, 2007).These expanded polyQ sequences in the HTT protein produce aggregates that form intracellular inclusions, leading to neural loss, particularly in the caudate nucleus (Rubinsztein and Carmichael, 2004).

Most studies aimed to find a clear correlation between HD and DNA methylation focus on two specific subjects: HTT gene and triplet repeat expansions. In addition to the genetic factors, environment also plays a vital role in this DNA methylation -associated mechanism.

\section{GENETIC FACTORS, DNA METHYLATION, AND HD}

Researches on DNA methylation in HD began much earlier than those in PD. In 1988, Wasmuth et al. reported the identification of a highly polymorphic locus, D4S95, which was demonstrated to be tightly linked to the HD gene (Wasmuth et al., 1988). Later, methylation was found at the B5 allele of the D4S95 locus, which was not inherited in a Mendelian fashion, as its appearance depended on the methylation status of the human lymphoblastoid cells from which DNA samples were obtained (Pritchard et al., 1989), and such phenomenon disclosed the secret of the role of DNA methylation in HD. For the first time, Farrer et al., in their study of 1764 HD patients explored that DNA methylation might be involved in a genetic imprinting mechanism, and thus responsible for the expression of HD (Farrer et al., 1992). Although a comparison between HD patients and normal controls showed no strong relevance between methylation and onset age of the disease, a significant association of the patient's age with demethylation at D4S95 was found (Reik et al., 1993). A PCRamplication of synthetic oligodeoxyribonucleotides revealed that cytidine methylation could have an impact on the expansion of triplet repeat sequences (Behnkrappa and Doerfler, 1994). Another finding that genome-wide demethylation could accelerate instability of CTG/CAG trinucleotide repeats in mammalian cells, implies that changes in methylation patterns during epigenetic reprograming may trigger the intergenerational repeat expansions, leading to neurological diseases like HD (Gorbunova et al., 2004).

It has been discovered that there is a region of highly unstable CAG repeats at the human spinocerebellar ataxia type 7 (SCA7) locus, and this region contains binding sites for CTCF, a regulatory factor involved in genomic imprinting, chromatin remodeling, and DNA conformation change (Filippova et al., 2001). Recently, an investigation in transgenic mice model found that CpG methylation of CTCF binding sites could further destabilize triplet repeat expansion (Libby et al., 2008), underpinning the role of DNA methylation in the regulation of neurological diseases. The HD-associated modification of BDNF gene expression was found, in the hippocampus of female and male HD mice independent of methylation increases in the gene sequence, while there existed a pattern of sex-specific differences in the levels of methylation at individual $\mathrm{CpG}$ sites, suggesting that such differences might explain the differential regulation of $B D N F$ expression in the male and female brains (Zajac et al., 2010). Since it has been reported that the loss of BDNF gene transcription is likely a central factor to the progressive pathology of HD, DNA methylation might be the explanation of such loss, which, however, needs further confirmation. Moreover, extensive changes in DNA methylation were reported to be linked to expression of mutant huntingtin gene, revealing the potential effects of DNA methylation alterations on neurogenesis and cognitive decline in patients with HD (Ng et al., 2013).

Besides, a recent study focused on adenosine $A_{2 A}$ receptor $\left(A_{2 A} R\right)$, a G-protein-coupled receptor, the expression levels of which are sharply reduced in HD (Villar-Menendez et al., 2013). The study found increased $5 \mathrm{mC}$ levels and reduced $5 \mathrm{hmC}$ levels in $5^{\prime} \mathrm{UTR}$ region of $\mathrm{A}_{2 \mathrm{~A}} \mathrm{R}$ gene from $\mathrm{HD}$ patients compared to agematched controls, suggesting an involvement of an altered methylation pattern of $A_{2 \mathrm{~A}} R$ gene in HD pathology. Moreover, instead of methylated cytosine, a HPLC-based method also detected levels of 7-methyl guanine in DNA samples both from transgenic mice and HD patients, revealing aberrant methylation levels in HD (Thomas et al., 2013), and also widening the range of future researches on DNA methylation.

\section{DNA METHYLATION AND AMYOTROPHIC LATERAL SCLEROSIS INTRODUCTION TO AMYOTROPHIC LATERAL SCLEROSIS}

ALS is an idiopathic, fatal neurodegenerative disease of the human motor system. The clinical hallmark of ALS is the presence of the lower motor neuron signs in brainstem and spinal cord, and the upper motor neuron signs in the motor cortex. Loss of 
these neurons leads to clinical phenotypes including muscle atrophy, weakness, fasciculation, spasticity, and cognitive dysfunction (Kiernan et al., 2011). Proposed pathogenic mechanisms for ALS include oxidative stress, glutamate excitotoxicity, impaired axonal transport, neurotrophic deprivation, neuroinflammation, apoptosis, and altered protein turnover, etc. Furthermore, influences from astrocytes and microglia in the motor neuron microenvironment contribute to ALS pathogenesis (de Carvalho and Swash, 2011).

ALS is traditionally classified into two categories: familial ALS (FALS) and sporadic ALS (SALS) (Robberecht and Philips, 2013). FALS is predominantly hereditary and then almost always autosomal dominant, while X-linked or recessive FALS is rare. Several genes and their mutations have been found to be associated with ALS. Superoxide dismutase 1 (SOD1) mutations are the cause in about $20 \%$ of FALS. Also, TARDBP, which encodes TAR DNAbinding protein, and FUS, a RNA- binding protein fused in sarcoma, also contribute to FALS cases. SALS has been associated with another gene, ELP3, encoding the catalytic subunit of the histone acetyltransferase (HAT) complex elongator protein (Urdinguio et al., 2009). Additionally, ALS2, ATXN2, and some other genes are also associated with ALS, which we will discuss below (Ferraiuolo et al., 2011).

Not unlike those neurodegenerative diseases we described above, there is a potential point that ALS is also connected to DNA methylation through genetic and environmental factors.

\section{GENETIC FACTORS, DNA METHYLATION, AND ALS}

An epigenetic analysis of SOD1 and VEGF (which encodes vascular endothelial growth factor, a signal protein produced by cells that stimulates vasculogenesis and angiogenesis) in ALS showed that the promoter regions of these genes were widely unmethylated in ALS patients, suggesting transcriptional silencing via DNA methylation is not likely a common mechanism in ALS (Oates and Pamphlett, 2007).

In contrast, methylation of the human glutamate transporter EAAT2 gene promoter has been reported to be associated with the silent state of the human EAAT2 gene. Since the dysfunction of EAAT2 transporter might contribute to the pathogenesis of ALS (Rothstein et al., 1995), it is meaningful to further test the regulation of EAAT2 transporter via an epigenetic mechanism including DNA methylation in ALS models. GLT1 is the analog to EAAT2 in rodent astroglial cells, however, hypermethylation on specific CpG islands of GLT1 promoter was discovered to participate in repression of GLT1 promoter activation, whereas this regulation was not involved in astroglial dysfunction of EAAT2 in ALS patients (Yang et al., 2010). Studies also found that a group of genes, either unsuspected in SALS or in potential pathways of cell death, revealed changed methylation status in SALS brains (Morahan et al., 2009). Because of the controversial findings above, there are supposed to be more powerful and convincing evidence collected to clarify the involvement of DNA methylation in ALS by regulating the expression of the human EAAT2.

In mouse models, the apoptosis process of motor neurons showed alterations in DNMT1, DNMT3a, and 5-methylcytosine, which is similar to those in human ALS, indicating that DNMT may mediate neuronal cell death through DNA methylation
(Chestnut et al., 2011). In addition, CpG methylation in human ATXN2 gene promoter is associated with pathogenic CAG expansions in spinocerebellar ataxia type 2 (SCA2) cases (Laffita-Mesa et al., 2012). Since such aberrant expansions in ATXN2 were shown to contribute to ALS (Lahut et al., 2012), we can expect that there might exist a link between ATXN2 promoter methylation and pathogenesis of ALS.

\section{ENVIRONMENTAL FACTORS AND DNA METHYLATION IN ALS}

Environmental exposure to heavy metals has been implicated in SALS and functionally impaired detoxification of these metals may cause serious susceptibility to the disease. The metallothionein (MT) is a family of proteins that are involved in primary detoxification mechanism for heavy metals. As a matter of fact, no promoter methylation of human MT genes was evident in any SALS or control samples, implying the possibility that methylation at these gene promoters may not be a common cause of SALS (Morahan et al., 2007). However, altered methylation of the Alsin (ALS2) gene promoter was observed in hippocampal cells of individuals with a history of being abused in childhood (Labonte et al., 2012). Interestingly, higher levels of promoter methylation were correlated with a repression of ALS transcription suggesting a role of DNA methylation in the regulation of ALS gene.

\section{DISCUSSION}

We find three topics worth discussing: (1) causal relationship between DNA methylation modification and neurodegenerative diseases, (2) triggers of DNA methylation modification in neurodegenerative diseases, and (3) perspectives.

In the field of neurodegenerative diseases, although experimental evidence revealed correlations between DNA methylation and these diseases, two major questions remain unclear. The first question is the causal relationship between DNA methylation modifications and neurodegenerative diseases. In other words, do DNA methylation modifications precede the appearance of neurodegenerative symptoms? Is there a proved mechanism demonstrating that DNA methylation modifications will finally lead to neurodegenerative diseases? Another question is: if DNA methylation modifications do cause neurodegenerative diseases, what is the trigger of these methylation modifications in neurodegenerative diseases? This is also a crucial question since it may lead us to new paths of curing these diseases.

\section{CAUSAL RELATIONSHIP BETWEEN DNA METHYLATION MODIFICATION AND NEURODEGENERATIVE DISEASES Alzheimer's disease}

Evidences generally suggested that DNA methylation modification is a cause instead of a consequence of $\mathrm{AD}$, for several events related to DNA methylation occur earlier than $\mathrm{AD}$ symptoms.

One clue is that the upregulation of plasma homocysteine (HCY), an independent $\mathrm{AD}$ risk factor, occurs prior to the pathogenesis of AD (Clarke et al., 1998; Seshadri et al., 2002). As we know, DNA methylation is accomplished by transferring a methyl group from SAM to the 5-position of cytosine. This metabolic pathway belongs to HCY metabolism (onecarbon metabolism). HCY accumulation leads to upregulation of S-adenosylhomocysteine (SAH) levels due to the reversibility 
of the reaction. To make the reaction proceed in the hydrolytic direction, HCY and Ado have to be efficiently removed (Fuso et al., 2005) (Figure 1). SAH, a strong DNA methyltransferase inhibitor, strengthens DNA hypomethylation. Thus, a regulation of metabolism through either remethylation or transsulfuration pathways may result in hyperhomocysteinemia, decrease of SAM/SAH ratio (also called methylation potential, MP), and change of GSH levels, suggesting that hypomethylation is a mechanism through which HCY is related to vascular disease and AD. Additionally, oxidative stress was shown to promote the production of HCY's oxidized derivatives, such as homocysteic acid and homocysteine sulfinic acid. These compounds interact with glutamate receptors thus increasing intracellular free radicals (Fuso and Scarpa, 2011). Following this trail, a series of studies demonstrated PS1 gene promoter hypomethylation in cell and mouse models under alterative HCY case (Scarpa et al., 2003; Fuso et al., 2005, 2007, 2008). These cases are often accomplished by deficiency of vitamin B6, vitamin B12 and folate during cell culture and mouse feeding. Moreover, in SK$\mathrm{N}$-BE neuroblastoma cells and TgCRND8 mice, such a trend is found to be reverted when SAM was intentionally added to the culture or diet (Fuso et al., 2011b). Cognitive experiments in mice and detection of $A \beta$ formation confirmed these results (Fuso et al., 2012b). It has also been shown that the activities of DNA methyltransferases (DNMT1, DNMT3A, DNMT3B) and demethylase (MBD2) are modulated by HCY metabolism in $\mathrm{AD}$ cells and mouse models. Elevated HCY levels decreased the activity of DNA methylase and the activity of DNA demethylase was increased (Fuso et al., 2011a). Since the elevation in the homocysteine level preceded the onset of dementia, studies from this area implies that global DNA hypomethylation is a cause of AD.

DNA methylation regulation in aging offers another clue to the causal relationship. Aging is generally considered to be one of the most salient risk factors for $\mathrm{AD}$, and a strong correlation between DNA methylation regulation and aging was demonstrated in brain and blood samples (Horvath et al., 2012). Decrement of S100A2 and increment in SORBS3 CpG methylation in the human cerebral cortex during aging was reported, and an acceleration of this trend was shown in AD patients (Siegmund et al., 2007). Another study including 24 LOAD brains and 10 matched controls revealed epigenetic variability of genes related to $\mathrm{AD}$ among all individuals, and AD patients' epigenetic distance from the norm was observed to increase progressively with age. It was suggested that epigenetic modifications may merely result in a range of interindividual variance until a threshold of epigenetic deregulation is reached. After this point, the brain starts to malfunction and $\mathrm{AD}$ symptoms occur. Based on this view, LOAD may represent an extreme form of normal aging (Wang et al., 2008). To sum up, these studies indicated that methylation changes are parts of aging, and some of them may result in AD.

It is noteworthy that there are results from another side. In a murine cerebral endothelial cells model, it was shown that $\mathrm{A} \beta$ reduces global DNA methylation whilst increasing NEP's DNA methylation level and further suppressing NEP's expression in mRNA and protein levels (Chen et al., 2009). This finding suggested a vicious cycle formed by DNA methylation alteration and $A \beta$ production, in which these two phenomena reinforce each other and cause $\mathrm{AD}$ eventually. This point is interesting, however, most other studies of this kind showed the opposite result. For instance, a recent study showed that amyloid production was not responsible for PS1 demethylation in the brain of TgCRND8 mice (carrying a double-mutated human APP transgene) (Fuso et al., 2012a). Therefore, such results need to be further analyzed.

\section{Parkinson's disease, Huntington's disease, and amyotrophic lateral sclerosis}

Similar to $\mathrm{AD}$, the other three major neurodegenerative diseases, i.e., $\mathrm{PD}, \mathrm{HD}$, and ALS, are also closely related to DNA methylation of several critical genetic loci. While these loci have been extensively studied, some findings seem to disagree with others. In the case of PD, $\alpha$-synuclein gene is the research spot of interest. There have been a series of studies of human PD brain cell samples that tested the DNA methylation level of the promoter and intron 1 of $\alpha$-synuclein gene and found a different methylation level compared to normal controls (Jowaed et al., 2010; Matsumoto et al., 2010; de Boni et al., 2011). These findings all support the idea that DNA methylation is involved in PD. However, some other results are not so positive as they found, while examining blood cell samples of PD patients, that $\alpha$-synuclein expression was not changed (Richter et al., 2012), or its expression changed independent of DNA methylation modification (Voutsinas et al., 2010). This seems a little controversial, but if we take a closer look at these results against the involvement of DNA methylation in PD, we can find that these examinations taken with blood cell samples are much less convincing than those taken with brain cell samples in that $\alpha$-synuclein is widely believed to mainly be localized and functional in mammalian brain neurons (Mclean et al., 2000; Yu et al., 2007). Other genetic loci with issues are parkin and UCHL1 genes, which also play important roles in $\mathrm{PD}$ pathology, however, due to lack of enough evidence so far, we still cannot determine whether these loci are affected by DNA methylation or not.

In the case of HD and ALS, the studies were merely focused on the rough relationship between these diseases and DNA methylation. Although, of course, there are some genetic loci that also have been examined in those researches such as CTCF, BDNF, and ATXN, we can barely come to any specific conclusion because of the poor quantity of scientific evidence.

\section{TRIGGERS OF DNA METHYLATION MODIFICATIONS IN NEURODEGENERATIVE DISEASES \\ Alzheimer's disease}

Knowing that DNA methylation changes do interact with $\mathrm{AD}$ and usually serve as causes, one may seek the origin of these changes in DNA methylation patterns. Such pursuit is worthwhile since it may finally guide us to a new path for treating $\mathrm{AD}$. We divide possible causes of DNA methylation regulation in $\mathrm{AD}$ into four aspects: aging, B vitamin deficiency, oxidative stress, and heavy metal exposure.

Aging factors. As we mentioned above, aging is a widely-accepted risk factor of $\mathrm{AD}$, and some reports regarded methylation change related to $\mathrm{AD}$ as an acceleration of aging (Siegmund et al., 2007) or a specialized case of aging (Wang et al., 2008). These studies 
provide a chain of causation from aging to DNA methylation deregulation and then to AD.

B vitamin deficiency. As we know, DNA methylation is accomplished by transferring a methyl group from SAM to the 5-position of cytosine and this metabolic pathway belongs to HCY metabolism (one-carbon metabolism). Folate, vitamin $\mathrm{B}_{6}$ and vitamin $\mathrm{B}_{12}$ are crucial for this metabolic cycle since $\mathrm{N}^{5}$ methyl-tetrahydrofolate ( $\mathrm{N}^{5}$-methyl-THF, a folate derivative) donates a methyl group to HCY that then transforms to methionine while vitamin $\mathrm{B}_{6}$ and vitamin $\mathrm{B}_{12}$ are involved in methylation catalysis. Therefore, the deficiency of vitamin B may block the regular DNA methylation metabolic cycle. This indication is supported by experimental evidence in rats (Miller et al., 1994), and B vitamin deficiency is commonly used as a method to create DNA methylation metabolism disorder in current studies (Fuso et al., 2005, 2011b; Chen et al., 2009). In addition to those hypermethylation and hypomethylation patterns we mentioned above, it was demonstrated that SAH increased DNA damage in BV- 2 cells possibly by increasing $A \beta$ formation that led to increased formation of ROS. Furthermore, the DNA damage was reinforced by SAH through inhibition of DNMT1 activity and hypomethylation of OGG1 gene promoter in microglial BV-2 cells (Lin et al., 2011).

Moreover, HCY inhibits the dimerization of ApoE3 and reduces ApoE3-mediated high-density lipoprotein (HDL) generation (Minagawa et al., 2010). It was shown that HDL apolipoproteins can significantly enhance the degradation of soluble $A \beta$ within microglia, and such degradation was facilitated by the lipidation of ApoE (Jiang et al., 2008). HCY was reported to impair ApoE3 dimerization and ApoE3's ability of generating HDL by binding to cysteine residues of ApoE3. Therefore, hyperhomocysteinemia may promote the pathogenesis of $\mathrm{AD}$ (Minagawa et al., 2010).

Oxidative stress. Causing the imbalance between DNA methylation and demethylation, oxidative stress is also known as an environmental factor interacting with DNA methylation and AD. Study in SH-SY5Y cells revealed that treatment with $\mathrm{H}_{2} \mathrm{O}_{2}$ may activate a DNMT inhibitor and result in the upregulation of APP and BACE1 through transcription activator-vB, leading to the upregulation of $A \beta$ production (Gu et al., 2013).

Heavy metal exposure. Infant exposure to lead $(\mathrm{Pb})$ was reported as another environmental factor contributing to $\mathrm{AD}$ through DNA methylation regulation. Developmental exposure of rodents to the heavy metal lead has been shown to increase APP and $\mathrm{A} \beta$ in aging brain (Basha et al., 2005). Study in aged monkeys showed that the group that was fed with $\mathrm{Pb}$ in their early life has a lower DNMT activity. The downregulation of DNMT activity thus results in the hypomethylation of several genes involved in $\mathrm{A} \beta$ formation such as APP and BACE, and causes the upregulation of APP, BACE, and Sp1 in turn, which finally results in $\mathrm{A} \beta$ formation and $\mathrm{AD}$ (Wu et al., 2008). These finding are confirmed by a genome-wide study on mice (Bihaqi et al., 2011) and an in vitro study (Bihaqi and Zawia, 2012). A latent early-life associated regulation (LEARn) model, which claims that environmental agents perturb gene regulation at early stage but do not have pathological results until later in life, was proposed to explain these phenomena (Lahiri et al., 2008; Lahiri and Maloney, 2012).

\section{Parkinson's disease, Huntington's disease, and amyotrophic lateral sclerosis}

Compared to $\mathrm{AD}$, the studies are relatively insufficient about the causal relationship between DNA methylation and other three neurodegenerative diseases as well as the causes of DNA methylation in these diseases. Despite paucity of evidences, a few studies showed that environmental factors such as exposure to toxicity like paraquat and previous physical and mental experiences like a history of being abused in childhood, are related to DNA methylation in these diseases. However, data we can search so far are so rough and random findings that no reliable conclusion but simply assumptions can be made from them. Therefore, we can see a promising field of interest waiting for further solid research findings to confirm the hypothesis that similar to $\mathrm{AD}$, there is also a causal relationship between DNA methylation and the other three neurodegenerative diseases (PD, HD, and ALS).

\section{PERSPECTIVES}

Expanding rapidly as it is, the field of DNA methylation and neurodegenerative diseases is facing three main challenges for further progress.

First of all, DNA methylation is an emerging field with many unclear issues. For instance, one may expect that the hypermethylation will result in the repression of a gene, however, some opposite findings have been reported, such as the coexistence of overexpression and DNA methylation of the p16INK4a gene (Kim and Sharpless, 2006). Without an accurate comprehension of the relationship between DNA methylation and the regulation of gene expression, much experimental evidence linking DNA methylation and neurodegenerative diseases may have been misinterpreted or missed. In addition, $5 \mathrm{hmC}$, which used to be regarded as only an intermediate in DNA demethylation, was recently found to increase with age in the absence of $5 \mathrm{mC}$ changes and thus may serve as an epigenetic factor of AD (Chen et al., 2012). With the majority of current studies concentrated on normal CpG methylation, we cannot ignore that non-CpG methylation and $5 \mathrm{hmC}$ also play an important role in DNA methylation. Since it has been suggested that non-CpG methylation and $5 \mathrm{hmC}$ are dominant in mammalian brain development (Lister et al., 2013), and since $5 \mathrm{hmC}$ is implicated in aging and AD (van den Hove et al., 2012), further studies should include these specific cases in order to give us a better understanding of how the DNA methylation is exactly related to the pathologies of neurodegenerative diseases.

Another challenge is that DNA methylation patterns vary in different cells as well as different brain regions. Study in human frontal cortex showed that neurons and glial cells do not share a same DNA methylation profile, nor do different neurons (Iwamoto et al., 2011). Since each type of cells in nervous system plays a distinct role, research ignoring variation among cells may not be able to provide sufficient evidence for this topic. Moreover, different regions of the brain, which have various importance in neurodegenerative diseases, were shown to express genes differently (Twine et al., 2011). Therefore, conclusions cannot be 
Table 1 | Altered DNA methylation profiles observed in neurodegenerative diseases.

\begin{tabular}{|c|c|c|c|c|}
\hline Disease & Category of genes & Specific genetic loci & DNA methylation regulation & Possible effect \\
\hline \multirow[t]{13}{*}{$A D$} & $A \beta$-related genes & $A P P$ & Hypomethylation or none & Over expression of $A \beta$ \\
\hline & & PSEN1 & Hypomethylation & \\
\hline & & APBA2 & Hypermethylation & \\
\hline & $A \beta$-degradation-related genes & $N E P$ & Hypermethylation & $A \beta$ accumulation \\
\hline & $\begin{array}{l}\text { Genes involved in metabolic } \\
\text { pathways }\end{array}$ & OTC & Hypomethylation & Metabolic dysfunction \\
\hline & rDNA & rDNA & Hypermethylation & Ribosomal deficits \\
\hline & Others & $\begin{array}{l}\text { Circadian gene (PER1 } \\
\text { and } C R Y 1)\end{array}$ & Hypermethylation & Behavioral and psychological symptoms \\
\hline & & $B D N F$ & Hypermethylation & Loss of neurotrophic factors \\
\hline & & CREB & Hypermethylation & Exacerbation of BDNF reduction \\
\hline & & SYP & Hypermethylation & Loss of synaptic proteins \\
\hline & & $N F-k B$ & Hypomethylation & Neuroinflammation \\
\hline & & S100A2 & Hypomethylation & Protein accumulation \\
\hline & & SORBS3 & Hypermethylation & Cell adhesion dysfunction \\
\hline \multirow[t]{4}{*}{ PD } & SNCA & $\begin{array}{l}\text { SNCA (intron1 and } \\
\text { promoter) }\end{array}$ & Hypermethylation & Decreased expression of SNCA \\
\hline & & & Hypomethylation & Overexpression of SNCA \\
\hline & Inflammatory cytokines & $T N F-\alpha$ & Hypomethylation & $\begin{array}{l}\text { Increased risk of apoptosis in } \\
\text { dopaminergic neurons }\end{array}$ \\
\hline & & Cytochrome P45 2E1 & Hypomethylation & Increased PD susceptibility \\
\hline \multirow[t]{5}{*}{ HD } & HTT gene & $\begin{array}{l}\text { Promoter region of HTT } \\
\text { gene }\end{array}$ & Extensive methylation alteration & Neurogenesis and cognition \\
\hline & Oligodeoxyribonucleotides & Cytidine & Hypermethylation & Expansion of triplet repeat sequences \\
\hline & Genome & Genome-wide & Hypomethylation & $\begin{array}{l}\text { Instability of CTG/CAG trinucleotide } \\
\text { repeats }\end{array}$ \\
\hline & CTCF & CTCF binding sites & CpG methylation & \\
\hline & $B D N F$ & $\begin{array}{l}\text { Promoter region of } \\
B D N F\end{array}$ & Gender-specific methylation & $\begin{array}{l}\text { Differential regulation of } B D N F \text { gene } \\
\text { expression }\end{array}$ \\
\hline \multirow[t]{4}{*}{ ALS } & $\begin{array}{l}\text { SOD1 } \\
\text { VEGF }\end{array}$ & $\begin{array}{l}\text { Promoter regions of } \\
\text { SOD1 and VEGF }\end{array}$ & Hypomethylation & No transcriptional silencing \\
\hline & EAAT2 & $\begin{array}{l}\text { Promoter regions of } \\
\text { EAAT2 }\end{array}$ & Hypermethylation & Functional loss of EAAT2 transporters \\
\hline & GLT1 & $\begin{array}{l}\text { Promoter region of } \\
\text { GLT1 }\end{array}$ & Hypermethylation & \\
\hline & ATXN2 & $\begin{array}{l}\text { Promoter region of } \\
\text { ATXN2 }\end{array}$ & Hypermethylation & Pathogenic CAG expansions \\
\hline
\end{tabular}


reached from studies merely focusing on one particular region of the brain.

The third challenge is the limitation in research methods. Most evidence of DNA methylation modification in neurodegenerative diseases was obtained from postmortem studies. Although this method was shown to preserve DNA methylation patterns successfully (Barrachina and Ferrer, 2009), it can only demonstrate the circumstance of one particular moment. Accordingly, the correlation between DNA methylation and neurodegenerative diseases can be revealed, but the time sequence of them is unable to be tracked. Such a limitation leads to the difficulty in determining the causal relationship of these events.

Hence, in the future, integrated and dynamic studies may significantly facilitate the development of this promising field. Comprehensive studies considering the difference among cell types and brain regions will certainly improve our understanding of this field. Furthermore, since DNA methylation is not an isolated process, studies must also consider interactions between DNA methylation and other epigenetic modifications such as histone acetylation. Although tracking the methylation status in a living animal cannot be achieved so far, it is possible to reach a dynamic perception via comparing postmortem results from samples with different ages, and such a strategy was used in some remarkable researches recently (Hon et al., 2013; Lister et al., 2013). Combined with the age-specific detection of neurodegenerative diseases, this type of studies will have great significance in uncovering the pathogenesis of neurodegenerative diseases, especially in the analysis of causal relationship between DNA methylation and such diseases.

\section{CONCLUSION}

In sum, the correlation between DNA methylation and neurodegenerative diseases has been pointed by numerous studies. These findings further indicated that DNA methylation alteration is one of the causes for neurodegenerative diseases (Table 1). As we discussed, environmental factors, as well as other possible factors like aging, are responsible for these alterations and may guide us to a new path of treating neurodegenerative diseases. Finally, this area is still filled with unsolved problems and waiting for further investigations to reveal these secrets, in order to give us a more comprehensive knowledge of how DNA methylation is involved in neurodegenerative diseases.

\section{ACKNOWLEDGMENTS}

We thank Dr. Immo Scheffler (Section of Molecular Biology, University of California San Diego, La Jolla, California, United States of America) for extensive language editing of this manuscript. This work was supported by National Natural Science Foundation of China (NSFC 81171206).

\section{REFERENCES}

Babenko, O., Kovalchuk, I., and Metz, G. A. (2012). Epigenetic programming of neurodegenerative diseases by an adverse environment. Brain Res. 1444, 96-111. doi: 10.1016/j.brainres.2012.01.038

Bakulski, K. M., Dolinoy, D. C., Sartor, M. A., Paulson, H. L., Konen, J. R., Lieberman, A. P., et al. (2012). Genome-wide DNA methylation differences between late-onset Alzheimer's disease and cognitively normal controls in human frontal cortex. J. Alzheimers Dis. 29, 571-588. doi: 10.3233/JAD-2012111223
Barrachina, M., and Ferrer, I. (2009). DNA methylation of Alzheimer disease and tauopathy-related genes in postmortem brain. J. Neuropathol. Exp. Neurol. 68, 880-891. doi: 10.1097/NEN.0b013e3181af2e46

Basha, M. R., Wei, W., Bakheet, S. A., Benitez, N., Siddiqi, H. K., Ge, Y. W., et al. (2005). The fetal basis of amyloidogenesis: exposure to lead and latent overexpression of amyloid precursor protein and beta-amyloid in the aging brain. J. Neurosci. 25, 823-829. doi: 10.1523/JNEUROSCI.4335-04.2005

Behnkrappa, A., and Doerfler, W. (1994). Enzymatic amplification of synthetic oligodeoxyribonucleotides: implication for triplet repeat expansions in the human genome. Human Mutat. 3, 19-24. doi: 10.1002/humu.1380030104

Bensemain, F., Hot, D., Ferreira, S., Dumont, J., Bombois, S., Maurage, C. A., et al. (2009). Evidence for induction of the ornithine transcarbamylase expression in Alzheimer's disease. Mol. Psychiatr. 14, 106-116. doi: 10.1038/sj.mp.4002089

Bestor, T. H. (2000). The DNA methyltransferases of mammals. Hum. Mol. Genet. 9, 2395-2402. doi: 10.1093/hmg/9.16.2395

Bhutani, N., Burns, D. M., and Blau, H. M. (2011). DNA demethylation dynamics. Cell 146, 866-872. doi: 10.1016/j.cell.2011.08.042

Bihaqi, S. W., Huang, H., Wu, J., and Zawia, N. H. (2011). Infant exposure to lead $(\mathrm{Pb})$ and epigenetic modifications in the aging primate brain: implications for Alzheimer's disease. J. Alzheimers Dis. 27, 819-833. doi: 10.3233/JAD-2011111013

Bihaqi, S. W., and Zawia, N. H. (2012). Alzheimer's disease biomarkers and epigenetic intermediates following exposure to $\mathrm{Pb}$ in vitro. Curr. Alzheimer Res. 9 , $555-562$.

Bird, A. (2002). DNA methylation patterns and epigenetic memory. Genes Dev. 16, 6-21. doi: 10.1101/gad.947102

Blandini, F., Fancellu, R., Martignoni, E., Mangiagalli, A., Pacchetti, Samuele, A., et al. (2001). Plasma homocysteine and L-DOPA metabolism in patients with Parkinson disease. Clin. Chem. 47, 1102-1104.

Bollati, V., Galimberti, D., Pergoli, L., Dalla Valle, E., Barretta, F., Cortini, F., et al. (2011). DNA methylation in repetitive elements and Alzheimer disease. Brain Behav. Immun. 25, 1078-1083. doi: 10.1016/j.bbi.2011.01.017

Bonsch, D., Lenz, B., Kornhuber, J., and Bleich, S. (2005). DNA hypermethylation of the alpha synuclein promoter in patients with alcoholism. Neuroreport 16, 167-170. doi: 10.1097/00001756-200502080-00020

Brattstrom, L. (2001). Plasma homocysteine and MTHFR C677T genotype in levodopa-treated patients with PD. Neurology 56, 281. doi: 10.1212/WNL.56.2.281

Brohede, J., Rinde, M., Winblad, B., and Graff, C. (2010). A DNA methylation study of the amyloid precursor protein gene in several brain regions from patients with familial Alzheimer disease. J. Neurogenet. 24, 179-181. doi: 10.3109/01677063.2010.503978

Byun, C. J., Seo, J., Jo, S. A., Park, Y. J., Klug, M., Rehli, M., et al. (2012). DNA methylation of the 5 '-untranslated region at +298 and +351 represses BACE1 expression in mouse BV-2 microglial cells. Biochem. Biophys. Res. Commun. 417, 387-392. doi: 10.1016/j.bbrc.2011.11.123

Cai, M., Tian, J., Zhao, G. H., Luo, W., and Zhang, B. R. (2011). Study of methylation levels of parkin gene promoter in Parkinson's disease patients. Int. J. Neurosci. 121, 497-502. doi: 10.3109/00207454.2011.580866

Cai, Y., Liu, S., Sothern, R. B., Xu, S., and Chan, P. (2010). Expression of clock genes Perl and Bmall in total leukocytes in health and Parkinson's disease. Eur. J. Neurol. 17, 550-554. doi: 10.1111/j.1468-1331.2009.02848.x

Chen, H., Dzitoyeva, S., and Manev, H. (2012). Effect of aging on 5hydroxymethylcytosine in the mouse hippocampus. Restor. Neurol. Neurosci. 30, 237-245. doi: 10.3233/RNN-2012-110223

Chen, K. L., Wang, S. S., Yang, Y. Y., Yuan, R. Y., Chen, R. M., and Hu, C. J. (2009). The epigenetic effects of amyloid-beta(1-40) on global DNA and neprilysin genes in murine cerebral endothelial cells. Biochem. Biophys. Res. Commun. 378, 57-61. doi: 10.1016/j.bbrc.2008.10.173

Chestnut, B. A., Chang, Q., Price, A., Lesuisse, C., Wong, M., and Martin, L. J. (2011). Epigenetic regulation of motor neuron cell death through DNA methylation. J. Neurosci. 31, 16619-16636. doi: 10.1523/JNEUROSCI.1639-11.2011

Chouliaras, L., Mastroeni, D., Delvaux, E., Grover, A., Kenis, G., Hof, P. R., et al. (2013). Consistent decrease in global DNA methylation and hydroxymethylation in the hippocampus of Alzheimer's disease patients. Neurobiol. Aging 34, 2091-2099. doi: 10.1016/j.neurobiolaging.2013.02.021

Chow, V. W., Mattson, M. P., Wong, P. C., and Gleichmann, M. (2010). An overview of APP processing enzymes and products. Neuromol. Med. 12, 1-12. doi: $10.1007 / \mathrm{s} 12017-009-8104-\mathrm{z}$ 
Clarke, R., Smith, A. D., Jobst, K. A., Refsum, H., Sutton, L., and Ueland, P. M. (1998). Folate, vitamin B-12, and serum total homocysteine levels in confirmed Alzheimer disease Arch. Neurol. 55, 1449-1455. doi: 10.1001/archneur.55.11.1449

Day, J. J., and Sweatt, J. D. (2010). DNA methylation and memory formation. Nat. Neurosci. 13, 1319-1323. doi: 10.1038/nn.2666

de Boni, L., Tierling, S., Roeber, S., Walter, J., Giese, A., and Kretzschmar, H. A. (2011). Next-Generation sequencing reveals regional differences of the alphasynuclein methylation state independent of Lewy body disease Neuromol. Med. 13, 310-320. doi: 10.1007/s12017-011-8163-9

de Carvalho, M., and Swash, M. (2011). Amyotrophic lateral sclerosis: an update. Curr. Opin. Neurol. 24, 497-503. doi: 10.1097/WCO.0b013e32834916a9

de Lau, L. M. L., and Breteler, M. M. B. (2006). Epidemiology of Parkinson's disease. Lancet Neurol. 5, 525-535. doi: 10.1016/S1474-4422(06)70471-9

Desplats, P., Spencer, B., Coffee, E., Patel, P., Michael, S., Patrick, C., et al. (2011). Alpha-synuclein sequesters Dnmtl from the nucleus: a novel mechanism for epigenetic alterations in Lewy body diseases. J. Biol. Chem. 286, 9031-9037. doi: 10.1074/jbc.C110.212589

Ding, Q., Markesbery, W. R., Chen, Q., Li, F., and Keller, J. N. (2005). Ribosome dysfunction is an early event in Alzheimer's disease. J. Neurosci. 25, 9171-9175. doi: 10.1523/JNEUROSCI.3040-05.2005

Dodge, J. E., Ramsahoye, B. H., Wo, Z. G., Okano, M., and Li, E. (2002). De novo methylation of MMLV provirus in embryonic stem cells: $\mathrm{CpG}$ versus non-CpG methylation. Gene 289, 41-48. doi: 10.1016/S0378-1119(02)00469-9

Duan, W., Ladenheim, B., Cutler, R. G., Kruman, I. I., Cadet, J. L., and Mattson, M. P. (2002). Dietary folate deficiency and elevated homocysteine levels endanger dopaminergic, neurons in models of Parkinson's disease. J. Neurochem. 80 101-110. doi: 10.1046/j.0022-3042.2001.00676.x

Edwards, J. R., O’Donnell, A. H., Rollins, R. A., Peckham, H. E., Lee, C., Milekic, M. H., et al. (2010). Chromatin and sequence features that define the fine and gross structure of genomic methylation patterns. Genome Res. 20, 972-980. doi: 10.1101/gr.101535.109

Farrer, L. A., Cupples, L. A., Kiely, D. K., Conneally, P. M., and Myers, R. H. (1992). Inverse relationship between age at onset of huntington disease and paternal age suggests involvement of genetic imprinting. Am. J. Hum. Genet. 50, 528-535.

Fatemi, M., and Wade, P. A. (2006). MBD family proteins: reading the epigenetic code. J. Cell. Sci. 119, 3033-3037. doi: 10.1242/jcs.03099

Ferraiuolo, L., Kirby, J., Grierson, A. J., Sendtner, M., and Shaw, P. J. (2011). Molecular pathways of motor neuron injury in amyotrophic lateral sclerosis. Nat. Rev. Neurol. 7, 616-630. doi: 10.1038/nrneurol.2011.152

Filippova, G. N., Thienes, C. P., Penn, B. H., Cho, D. H., Hu, Y. J., Moore, J. M., et al. (2001). CTCF-binding sites flank CTG/CAG repeats and form a methylation-sensitive insulator at the DM1 locus. Nat. Genet. 28, 335-343. doi: $10.1038 /$ ng570

Fraga, M. F., Ballestar, E., Paz, M. F., Ropero, S., Setien, F., Ballestar, M. L., et al. (2005). Epigenetic differences arise during the lifetime of monozygotic twins. Proc. Natl. Acad. Sci. U.S.A. 102, 10604-10609. doi: 10.1073/pnas.0500398102

Furuya, T. K., da Silva, P. N., Payao, S. L., Rasmussen, L. T., de Labio, R. W., Bertolucci, P. H., et al. (2012a). SORL1 and SIRT1 mRNA expression and promoter methylation levels in aging and Alzheimer's disease. Neurochem. Int. 61 , 973-975. doi: 10.1016/j.neuint.2012.07.014

Furuya, T. K., Silva, P. N., Payao, S. L., Bertolucci, P. H., Rasmussen, L. T., de Labio, R. W., et al. (2012b). Analysis of SNAP25 mRNA expression and promoter DNA methylation in brain areas of Alzheimer's disease patients. Neuroscience 220, 41-46. doi: 10.1016/j.neuroscience.2012.06.035

Fuso, A., Cavallaro, R. A., Nicolia, V., and Scarpa, S. (2012a). PSEN1 promoter demethylation in hyperhomocysteinemic TgCRND8 mice is the culprit, not the consequence. Curr. Alzheimer Res. 9, 527-535.

Fuso, A., Nicolia, V., Ricceri, L., Cavallaro, R. A., Isopi, E., Mangia, F., et al. (2012b). S-adenosylmethionine reduces the progress of the Alzheimer-like features induced by B-vitamin deficiency in mice. Neurobiol. Aging 33, 1482.e1-1482.e16. doi: 10.1016/j.neurobiolaging.2011.12.013

Fuso, A., Cavallaroa, R. A., Zampellia, A., D’Anselmia, F., Piscopob, P., Confalonib, A., et al. (2007). $\gamma$-secretase is differentially modulated by alteration of homocysteine cycle in neuroblastoma and glioblastoma cells. J. Alzheimers Dis. 11, 275-290.

Fuso, A., Nicolia, V., Cavallaro, R. A., Ricceri, L., D’Anselmi, F., Coluccia, P., et al. (2008). B-vitamin deprivation induces hyperhomocysteinemia and brain S-adenosylhomocysteine, depletes brain S-adenosylmethionine, and enhances
PS1 and BACE expression and amyloid-beta deposition in mice. Mol. Cell. Neurosci. 37, 731-746. doi: 10.1016/j.mcn.2007.12.018

Fuso, A., Nicolia, V., Cavallaro, R. A., and Scarpa, S. (2011a). DNA methylase and demethylase activities are modulated by one-carbon metabolism in Alzheimer's disease models. J. Nutr. Biochem. 22, 242-251. doi: 10.1016/j.jnutbio.2010.01.010

Fuso, A., Nicolia, V., Pasqualato, A., Fiorenza, M. T., Cavallaro, R. A., and Scarpa, S. (2011b). Changes in Presenilin 1 gene methylation pattern in diet-induced B vitamin deficiency. Neurobiol. Aging 32, 187-199. doi: 10.1016/j.neurobiolaging.2009.02.013

Fuso, A., and Scarpa, S. (2011). One-carbon metabolism and Alzheimer's disease: is it all a methylation matter? Neurobiol. Aging 32, 1192-1195. doi: 10.1016/j.neurobiolaging.2011.01.012

Fuso, A., Seminara, L., Cavallaro, R. A., D’Anselmi, F., and Scarpa, S. (2005). S-adenosylmethionine/homocysteine cycle alterations modify DNA methylation status with consequent deregulation of PS1 and BACE and beta-amyloid production. Mol. Cell. Neurosci. 28, 195-204. doi: 10.1016/j.mcn.2004.09.007

Goll, M. G., Kirpekar, F., Maggert, K. A., Yoder, J. A., Hsieh, C. L., Zhang, X., et al. (2006). Methylation of tRNAAsp by the DNA methyltransferase homolog Dnmt2. Science 311, 395-398. doi: 10.1126/science.1120976

Gorbunova, V., Seluanov, A., Mittelman, D., and Wilson, J. H. (2004). Genomewide demethylation destabilizes CTG.CAG trinucleotide repeats in mammalian cells. Hum. Mol. Genet. 13, 2979-2989. doi: 10.1093/hmg/ddh317

Gu, X., Sun, J., Li, S., Wu, X., and Li, L. (2013). Oxidative stress induces DNA demethylation and histone acetylation in SH-SY5Y cells: potential epigenetic mechanisms in gene transcription in Abeta production. Neurobiol. Aging 34, 1069-1079. doi: 10.1016/j.neurobiolaging.2012.10.013

Guan, J. Z., Guan, W. P., Maeda, T., and Makino, N. (2012). Effect of vitamin E administration on the elevated oxygen stress and the telomeric and subtelomeric status in Alzheimer's disease. Gerontology 58, 62-69. doi: 10.1159/000327821

Guan, J. Z., Maeda, T., Sugano, M., Oyama, J., Higuchi, Y., Suzuki, T., et al. (2008). A percentage analysis of the telomere length in Parkinson's disease patients. J. Gerontol. A Biol. Sci. Med. Sci. 63, 467-473. doi: 10.1093/gerona/63.5.467

Guo, J. U., Su, Y., Zhong, C., Ming, G. L., and Song, H. (2011a). Hydroxylation of 5-methylcytosine by TET1 promotes active DNA demethylation in the adult brain. Cell 145, 423-434. doi: 10.1016/j.cell.2011.03.022

Guo, X., Wu, X., Ren, L., Liu, G., and Li, L. (2011b). Epigenetic mechanisms of amyloid-beta production in anisomycin-treated SH-SY5Y cells. Neuroscience 194, 272-281. doi: 10.1016/j.neuroscience.2011.07.012

Haines, T. R., Rodenhiser, D. I., and Ainsworth, P. J. (2001). Allele-specific nonCpG methylation of the Nf1 gene during early mouse development. Dev. Biol. 240, 585-598. doi: 10.1006/dbio.2001.0504

Hon, G. C., Rajagopal, N., Shen, Y., Mccleary, D. F., Yue, F., Dang, M. D. et al. (2013). Epigenetic memory at embryonic enhancers identified in DNA methylation maps from adult mouse tissues. Nat. Genet. 45, 1198-1206. doi: 10.1038/ng.2746

Hood, S., Cassidy, P., Cossette, M. P., Weigl, Y., Verwey, M., Robinson, B., et al. (2010). Endogenous dopamine regulates the rhythm of expression of the clock protein PER2 in the rat dorsal striatum via daily activation of D2 dopamine receptors. J. Neurosci. 30, 14046-14058. doi: 10.1523/JNEUROSCI.212810.2010

Horvath, S., Zhang, Y., Langfelder, P., Kahn, R. S., Boks, M. P., van Eijk, K., et al. (2012). Aging effects on DNA methylation modules in human brain and blood tissue. Genome Biol. 13:R97. doi: 10.1186/gb-2012-13-10-r97

Hotchkiss, R. D. (1948). The quantitative separation of purines, pyrimidines, and nucleosides by paper chromatography. J. Biol. Chem. 175, 315-332.

Ittner, L. M., and Gotz, J. (2011). Amyloid-beta and tau-a toxic pas de deux in Alzheimer's disease. Nat. Rev. Neurosci. 12, 65-72. doi: 10.1038/nrn2967

Iwamoto, K., Bundo, M., Ueda, J., Oldham, M. C., Ukai, W., Hashimoto, E., et al. (2011). Neurons show distinctive DNA methylation profile and higher interindividual variations compared with non-neurons. Genome Res. 21, 688-696. doi: 10.1101/gr.112755.110

Iwata, N., Tsubuki, S., Takaki, Y., Watanabe, K., Sekiguchi, M., Hosoki, E., et al. (2000). Identification of the major Abeta1-42-degrading catabolic pathway in brain parenchyma: suppression leads to biochemical and pathological deposition. Nat. Med. 6, 143-150. doi: 10.1038/77399

Jiang, Q., Lee, C. Y., Mandrekar, S., Wilkinson, B., Cramer, P., Zelcer, N., et al. (2008). ApoE promotes the proteolytic degradation of Abeta. Neuron 58, 681-693. doi: 10.1016/j.neuron.2008.04.010 
Jin, H., Kanthasamy, A., Ghosh, A., Yang, Y., Anantharam, V., and Kanthasamy, A. G. (2011). alpha-Synuclein negatively regulates protein kinase Cdelta expression to suppress apoptosis in dopaminergic neurons by reducing $\mathrm{p} 300$ histone acetyltransferase activity. J. Neurosci. 31, 2035-2051. doi: 10.1523/JNEUROSCI.563410.2011

Jowaed, A., Schmitt, I., Kaut, O., and Wullner, U. (2010). Methylation regulates alpha-synuclein expression and is decreased in Parkinson's disease patients' brains. J. Neurosci. 30, 6355-6359. doi: 10.1523/JNEUROSCI.6119-09.2010

Kagara, I., Enokida, H., Kawakami, K., Matsuda, R., Toki, K., Nishimura, H., et al. (2008). CpG hypermethylation of the UCHL1 gene promoter is associated with pathogenesis and poor prognosis in renal cell carcinoma. J. Urology 180, 343-351. doi: 10.1016/j.juro.2008.02.044

Kalbe, E., Kessler, J., Calabrese, P., Smith, R., Passmore, A. P., Brand, M., et al. (2004). DemTect: a new, sensitive cognitive screening test to support the diagnosis of mild cognitive impairment and early dementia. Int. J. Geriatr. Psychiatry 19, 136-143. doi: 10.1002/gps.1042

Kaut, O., Schmitt, I., and Wullner, U. (2012). Genome-scale methylation analysis of Parkinson's disease patients' brains reveals DNA hypomethylation and increased mRNA expression of cytochrome P450 2E1. Neurogenetics 13, 87-91. doi: 10.1007/s10048-011-0308-3

Khan, A. A., Mao, X. O., Banwait, S., Jin, K., and Greenberg, D. A. (2007). Neuroglobin attenuates -amyloid neurotoxicity in vitro and transgenic Alzheimer phenotype in vivo. Proc. Natl. Acad. Sci. U.S.A. 104, 19114-19119. doi: 10.1073/pnas.0706167104

Kiernan, M., Vucic, S., Cheah, B., Turner, M., Eisen, A., Hardiman, O., et al. (2011). Amyotrophic lateral sclerosis. Lancet 377, 942-955. doi: 10.1016/S01406736(10)61156-7

Kim, W. Y., and Sharpless, N. E. (2006). The regulation of INK4/ARF in cancer and aging. Cell 127, 265-275. doi: 10.1016/j.cell.2006.10.003

Kong, M., Ba, M., Liang, H., Ma, L., Yu, Q., Yu, T., et al. (2012). 5'-Aza-dC sensitizes paraquat toxic effects on PC12 cell. Neurosci. Lett. 524, 35-39. doi: 10.1016/j.neulet.2012.07.001

Kriaucionis, S., and Heintz, N. (2009). The nuclear DNA base 5hydroxymethylcytosine is present in Purkinje neurons and the brain. Science 324, 929-930. doi: 10.1126/science.1169786

Kurochkin, I. V., and Goto, S. (1994). Alzheimer's beta-amyloid peptide specifically interacts with and is degraded by insulin degrading enzyme. FEBS Lett. 345, 33-37. doi: 10.1016/0014-5793(94)00387-4

Labonte, B., Suderman, M., Maussion, G., Navaro, L., Yerko, V., Mahar, I., et al. (2012). Genomer-wide epigenetic regulation by early-life trauma. Arch. Gen. Psychiatry 69, 722-731. doi: 10.1001/archgenpsychiatry.2011.2287

Laffita-Mesa, J., Bauer, P., Kouri, V., Serrano, L., Roskams, J., Gotay, D., et al. (2012). Epigenetics DNA methylation in the core ataxin-2 gene promoter: novel physiological and pathological implications. Hum. Genet. 131, 625-638. doi: 10.1007/s00439-011-1101-y

Lahiri, D. K., and Maloney, B. (2012). The "LEARn" (latent early-life associated regulation) model: an epigenetic pathway linking metabolic and cognitive disorders. J. Alzheimers Dis. 30(Suppl. 2), S15-S30. doi: 10.3233/JAD-2012-120373

Lahiri, D. K., Zawia, N. H., Greig, N. H., Sambamurti, K., and Maloney, B. (2008). Early-life events may trigger biochemical pathways for Alzheimer's disease: the "LEARn" model. Biogerontology 9, 375-379. doi: 10.1007/s10522-008-9162-6

Lahut, S., Omur, O., Uyan, O., Agim, Z. S., Ozoguz, A., Parman, Y., et al. (2012). ATXN2 and its neighbouring gene SH2B3 are associated with increased ALS risk in the Turkish population. PLoS ONE 7:e42956. doi: 10.1371/journal.pone.0042956

Libby, R. T., Hagerman, K. A., Pineda, V. V., Lau, R., Cho, D. H., Baccam, S. L., et al. (2008). CTCF cis-regulates trinucleotide repeat instability in an epigenetic manner: a novel basis for mutational hot spot determination. PLoS Genet. 4:e1000257. doi: 10.1371/journal.pgen.1000257

Lin, H. C., Song, T. Y., and Hu, M. L. (2011). S-Adenosylhomocysteine enhances DNA damage through increased beta-amyloid formation and inhibition of the DNA-repair enzyme OGG1b in microglial BV-2 cells. Toxicology 290, 342-349. doi: 10.1016/j.tox.2011.10.016

Lin, Q., Ding, H., Zheng, Z., Gu, Z., Ma, J., Chen, L., et al. (2012). Promoter methylation analysis of seven clock genes in Parkinson's disease. Neurosci. Lett. 507, 147-150. doi: 10.1016/j.neulet.2011.12.007

Lister, R., Mukamel, E. A., Nery, J. R., Urich, M., Puddifoot, C. A., Johnson, N. D., et al. (2013). Global epigenomic reconfiguration during mammalian brain development. Science 341, 1237905. doi: 10.1126/science.1237905
Lister, R., Pelizzola, M., Dowen, R. H., Hawkins, R. D., Hon, G., Tonti-Filippini, J., et al. (2009). Human DNA methylomes at base resolution show widespread epigenomic differences. Nature 462, 315-322. doi: 10.1038/nature08514

Liu, H. C., Hu, C. J., Tang, Y. C., and Chang, J. G. (2008). A pilot study for circadian gene disturbance in dementia patients. Neurosci. Lett. 435, 229-233. doi: 10.1016/j.neulet.2008.02.041

Maeda, T., Guan, J. Z., Oyama, J., Higuchi, Y., and Makino, N. (2009). Agingassociated alteration of subtelomeric methylation in Parkinson's disease. J. Gerontol. A Biol. Sci. Med. Sci. 64, 949-955. doi: 10.1093/gerona/glp070

Mastroeni, D., Grover, A., Delvaux, E., Whiteside, C., Coleman, P. D., and Rogers, J. (2010). Epigenetic changes in Alzheimer's disease: decrements in DNA methylation. Neurobiol. Aging 31, 2025-2037. doi: 10.1016/j.neurobiolaging.2008.12.005

Mastroeni, D., Grover, A., Delvaux, E., Whiteside, C., Coleman, P. D., and Rogers, J. (2011). Epigenetic mechanisms in Alzheimer's disease. Neurobiol. Aging 32, 1161-1180. doi: 10.1016/j.neurobiolaging.2010.08.017

Mastroeni, D., Mckee, A., Grover, A., Rogers, J., and Coleman, P. (2009). Epigenetic differences in cortical neurons from a pair of monozygotic twins discordant for Alzheimer's disease. PLoS ONE 4:e6617. doi: 10.1371/journal.pone.0006617

Matsumoto, L., Takuma, H., Tamaoka, A., Kurisaki, H., Date, H., Tsuji, S., et al. (2010). CpG demethylation enhances alpha-synuclein expression and affects the pathogenesis of Parkinson's disease. PLoS ONE 5:e15522. doi: 10.1371/journal.pone.0015522

Mclean, P. J., Kawamata, H., Ribich, S., and Hyman, B. T. (2000). Membrane association and protein conformation of alpha-synuclein in intact neurons-effect of Parkinson's disease-linked mutations. J. Biol. Chem. 275, 8812-8816. doi: $10.1074 / \mathrm{jbc} .275 .12 .8812$

Miller, C. A., Campbell, S. L., and Sweatt, J. D. (2008). DNA methylation and histone acetylation work in concert to regulate memory formation and synaptic plasticity. Neurobiol. Learn. Mem. 89, 599-603. doi: 10.1016/j.nlm.2007.07.016

Miller, J., Nadeau, M., Smith, D., and Selhub, J. (1994). Vitamin B-6 deficiency vs. folate deficiency: comparison of responses to methionine loading in rats. Am. J. Clin. Nutr. 59, 1033-1039.

Minagawa, H., Watanabe, A., Akatsu, H., Adachi, K., Ohtsuka, C., Terayama, Y., et al. (2010). Homocysteine, another risk factor for Alzheimer disease, impairs apolipoprotein E3 function. J. Biol. Chem. 285, 38382-38388. doi: 10.1074/jbc.M110.146258

Mogi, M., Harada, M., Narabayashi, H., Inagaki, H., Minami, M., and Nagatsu, T. (1996). Interleukin (IL)-1 beta, IL-2, IL-4, IL-6 and transforming growth factor-alpha levels are elevated in ventricular cerebrospinal fluid in juvenile parkinsonism and Parkinson's disease. Neurosci. Lett. 211, 13-16. doi: 10.1016/0304-3940(96)12706-3

Morahan, J. M., Yu, B., Trent, R. J., and Pamphlett, R. (2007). Are metallothionein genes silenced in ALS? Toxicol. Lett. 168, 83-87. doi: 10.1016/j.toxlet.2006.11.003

Morahan, J. M., Yu, B., Trent, R. J., and Pamphlett, R. (2009). A genome-wide analysis of brain DNA methylation identifies new candidate genes for sporadic amyotrophic lateral sclerosis. Amyotroph Lateral Scler. 10, 418-429. doi: $10.3109 / 17482960802635397$

Ng, C. W., Yildirim, F., Yap, Y. S., Dalin, S., Matthews, B. J., Velez, P. J., et al. (2013). Extensive changes in DNA methylation are associated with expression of mutant huntingtin. Proc. Natl. Acad. Sci. U.S.A. 110, 2354-2359. doi: 10.1073/pnas. 1221292110

Nicolia, V., Fuso, A., Cavallaro, R. A., Di Luzio, A., and Scarpa, S. (2010). B vitamin deficiency promotes tau phosphorylation through regulation of GSK3beta and PP2A. J. Alzheimers Dis. 19, 895-907. doi: 10.3233/JAD-2010-1284

Oates, N., and Pamphlett, R. (2007). An epigenetic analysis of SOD1 and VEGF in ALS. Amyotroph. Lateral Scler. 8, 83-86. doi: 10.1080/17482960601149160

Obeid, R., Schadt, A., Dillmann, U., Kostopoulos, P., Fassbender, K., and Herrmann, W. (2009). Methylation status and neurodegenerative markers in Parkinson disease. Clin. Chem. 55, 1852-1860. doi: 10.1373/clinchem.2009.125021

Offe, K., Dodson, S. E., Shoemaker, J. T., Fritz, J. J., Gearing, M., Levey, A. I., et al. (2006). The lipoprotein receptor LR11 regulates amyloid beta production and amyloid precursor protein traffic in endosomal compartments. J. Neurosci. 26, 1596-1603. doi: 10.1523/JNEUROSCI.4946-05.2006

O'Suilleabhain, P. E., Sung, V., Hernandez, C., Lacritz, L., Dewey, B. R., Bottiglieri, T., et al. (2004). Elevated plasma homocysteine level in patients with Parkinson disease. Arch. Neurol. 61, 865-868. doi: 10.1001/archneur.61.6.865 
Paul, L. (2011). Diet, nutrition and telomere length. J. Nutr. Biochem. 22, 895-901. doi: 10.1016/j.jnutbio.2010.12.001

Paul, L., Cattaneo, M., D’Angelo, A., Sampietro, F., Fermo, I., Razzari, C., et al. (2009). Telomere length in peripheral blood mononuclear cells is associated with folate status in men. J. Nutr. 139, 1273-1278. doi: 10.3945/jn.109. 104984

Penn, N. W., Suwalski, R., O’Riley, C., Bojanowski, K., and Yura, R. (1972). Presence of 5-hydroxymethylcytosine in animal deoxyribonucleic acid. Biochem. J. 126, 781-790.

Pieper, H. C., Evert, B. O., Kaut, O., Riederer, P. F., Waha, A., and Wullner, U. (2008). Different methylation of the TNF-alpha promoter in cortex and substantia nigra: Implications for selective neuronal vulnerability. Neurobiol. Dis. 32, 521-527. doi: 10.1016/j.nbd.2008.09.010

Pietrzak, M., Rempala, G., Nelson, P. T., Zheng, J. J., and Hetman, M. (2011). Epigenetic silencing of nucleolar rRNA genes in Alzheimer's disease. PLoS ONE 6:e22585. doi: 10.1371/journal.pone.0022585

Plagnol, V., Nalls, M. A., Bras, J. M., Hernandez, D. G., Sharma, M., Sheerin, U. M., et al. (2011). A two-stage meta-analysis identifies several new loci for Parkinson's disease. PLoS Genet. 7:e1002142. doi: 10.1371/journal.pgen. 1002142

Popkie, A. P., Zeidner, L. C., Albrecht, A. M., D'Ippolito, A., Eckardt, S., Newsom, D. E., et al. (2010). Phosphatidylinositol 3-kinase (PI3K) signaling via glycogen synthase kinase-3 (Gsk-3) regulates DNA methylation of imprinted loci. J. Biol. Chem. 285, 41337-41347. doi: 10.1074/jbc.M110. 170704

Pritchard, C. A., Cox, D. R., and Myers, R. M. (1989). Methylation at the Huntington disease-linked D4S95 locus. Am. J. Hum. Genet. 45, 335-336.

Rao, J. S., Keleshian, V. L., Klein, S., and Rapoport, S. I. (2012). Epigenetic modifications in frontal cortex from Alzheimer's disease and bipolar disorder patients. Transl. Psychiatry 2:e132. doi: 10.1038/tp.2012.55

Reik, W., Dean, W., and Walter, J. (2001). Epigenetic reprogramming in mammalian development. Science 293, 1089-1093. doi: 10.1126/science.1063443

Reik, W., Maher, E. R., Morrison, P. J., Harding, A. E., and Simpson, S. A. (1993). Age at onset in Huntington's disease and methylation at D4S95. J. Med. Genet. 30, 185-188. doi: 10.1136/jmg.30.3.185

Richter, J., Appenzeller, S., Ammerpohl, O., Deuschl, G., Paschen, S., Brueggemann, N., et al. (2012). No evidence for differential methylation of alpha-synuclein in leukocyte DNA of Parkinson's disease patients. Movement Disord. 27, 590-591. doi: $10.1002 / \mathrm{mds} .24907$

Robberecht, W., and Philips, T. (2013). The changing scene of amyotrophic lateral sclerosis. Nat. Rev. Neurosci. 14, 248-264. doi: 10.1038/nrn3430

Roses, A. D., Saunders, A. M., Corder, E. H., Pericakvance, M. A., Han, S. H., Einstein, G., et al. (1995). Influence of the susceptibility genes apolipoprotein E-epsilon 4 and apolipoprotein E-epsilon 2 on the rate of disease expressivity of late-onset Alzheimer's disease. Arzneimittelforschung 45-41, 413-417.

Rothstein, J. D., Vankammen, M., Levey, A. I., Martin, L. J., and Kuncl, R. W. (1995). Selective loss of glial glutamate transporter GLT-1 in amyotrophiclateralsclerosis. Ann. Neurol. 38, 73-84. doi: 10.1002/ana.410380114

Rubinsztein, D. C., and Carmichael, J. (2004). Huntington's disease: molecular basis of neurodegeneration. Expert Rev. Mol. Med. 5, 1-21. doi: $10.1017 / S 1462399403006549$

Scarpa, S., Cavallaro, R. A., D'Anselmi, F., and Fuso, A. (2006). Gene silencing through methylation: an epigenetic intervention on Alzheimer disease. J. Alzheimers Dis. 9, 407-414.

Scarpa, S., Fuso, A., D'Anselmi, F., and Cavallaro, R. A. (2003). Presenilin 1 gene silencing by S-adenosylmethionine: a treatment for Alzheimer disease? FEBS Lett. 541, 145-148. doi: 10.1016/S0014-5793(03)00277-1

Seshadri, S., Beiser, A., Selhub, J., Jacques, P. F., Rosenberg, I. H., D’Agostino, R. B., et al. (2002). Plasma homocysteine as a risk factor for dementia and Alzheimer's disease. New Engl. J. Med. 346, 476-483. doi: 10.1056/NEJMoa011613

Siegmund, K. D., Connor, C. M., Campan, M., Long, T. I., Weisenberger, D. J., Biniszkiewicz, D., et al. (2007). DNA methylation in the human cerebral cortex is dynamically regulated throughout the life span and involves differentiated neurons. PLoS ONE 2:e895. doi: 10.1371/journal.pone.0000895

Silva, P. N., Furuya, T. K., Sampaio Braga, I., Rasmussen, L. T., de Labio, R. W., Bertolucci, P. H., et al. (2013). CNP and DPYSL2 mRNA expression and promoter methylation levels in brain of Alzheimer's disease patients. J. Alzheimers Dis. 33, 349-355. doi: 10.3233/JAD-2012-121192
Silva, P. N. O., Gigek, C. O., Leal, M. F., Bertolucci, P. H. F., de Labio, R. W., Payao, S. L. M., et al. (2008). Promoter methylation analysis of SIRT3, SMARCA5, HTERT and CDH1 genes in aging and Alzheimer's disease. J. Alzheimers Dis. $13,173-176$.

Speranca, M. A., Batista, L. M., Lourenco Rda, S., Tavares, W. M., Bertolucci, P. H., Rigolin Vde, O., et al. (2008). Can the rDNA methylation pattern be used as a marker for Alzheimer's disease? Alzheimers Dement. 4, 438-442. doi: 10.1016/j.jalz.2008.03.010

Sung, H. Y., Choi, E. N., Ahn Jo, S., Oh, S., and Ahn, J. H. (2011). Amyloid protein-mediated differential DNA methylation status regulates gene expression in Alzheimer's disease model cell line. Biochem. Biophys. Res. Commun. 414, 700-705. doi: 10.1016/j.bbrc.2011.09.136

Tahiliani, M., Koh, K. P., Shen, Y., Pastor, W. A., Bandukwala, H., Brudno, Y., et al. (2009). Conversion of 5-methylcytosine to 5-hydroxymethylcytosine in mammalian DNA by MLL partner TET1. Science 324, 930-935. doi: 10.1126/science. 1170116

Thies, W., Bleiler, L., and Assoc, A. S. (2013). 2013 Alzheimer's disease facts and figures. Alzheimers Dement. 9, 208-245. doi: 10.1016/j.jalz.2013.02.003

Thomas, B., Matson, S., Chopra, V., Sun, L., Sharma, S., Hersch, S., et al. (2013). A novel method for detecting 7-methyl guanine reveals aberrant methylation levels in Huntington disease. Anal. Biochem. 436, 112-120. doi: 10.1016/j.ab.2013.01.035

Twine, N. A., Janitz, K., Wilkins, M. R., and Janitz, M. (2011). Whole transcriptome sequencing reveals gene expression and splicing differences in brain regions affected by Alzheimer's disease. PLoS ONE 6:e16266. doi: 10.1371/journal.pone.0016266

Urdinguio, R. G., Sanchez-Mut, J. V., and Esteller, M. (2009). Epigenetic mechanisms in neurological diseases: genes, syndromes, and therapies. Lancet Neurol. 8, 1056-1072. doi: 10.1016/S1474-4422(09)70262-5

van den Hove, D. L. A., Chouliaras, L., and Rutten, B. P. F. (2012). The Role of 5-Hydroxymethylcytosine in aging and Alzheimer's disease: current status and prospects for future studies. Curr. Alzheimer Res. 9, 545-549.

van der Flier, W. M., Pijnenburg, Y.a.L., Fox, N. C., and Scheltens, P. (2011). Early-onset versus late-onset Alzheimer's disease: the case of the missing APOE ?4 allele. Lancet Neurol. 10, 280-288. doi: 10.1016/S1474-4422(10) 70306-9

van Heesbeen, H. J., Mesman, S., Veenvliet, J. V., and Smidt, M. P. (2013). Epigenetic mechanisms in the development and maintenance of dopaminergic neurons. Development 140, 1159-1169. doi: 10.1242/dev.089359

Villar-Menendez, I., Blanch, M., Tyebji, S., Pereira-Veiga, T., Albasanz, J. L., Martin, M., et al. (2013). Increased 5-methylcytosine and decreased 5hydroxymethylcytosine levels are associated with reduced striatal A(2A)R levels in Huntington's disease. Neuromol. Med. 15, 295-309. doi: 10.1007/s12017-0138219-0

Voutsinas, G. E., Stavrou, E. F., Karousos, G., Dasoula, A., Papachatzopoulou, A., Syrrou, M., et al. (2010). Allelic imbalance of expression and epigenetic regulation within the alpha-synuclein wild-type and p.Ala53Thr alleles in Parkinson disease. Hum. Mutat. 31, 685-691. doi: 10.1002/humu.21248

Walker, F. O. (2007). Huntington's disease. Lancet 369, 218-228. doi: 10.1016/S0140-6736(07)60111-1

Wang, S. C., Oelze, B., and Schumacher, A. (2008). Age-specific epigenetic drift in late-onset Alzheimer's disease. PLoS ONE 3:e2698. doi: 10.1371/journal.pone. 0002698

Wang, Y., Wang, X., Li, R., Yang, Z. F., Wang, Y. Z., Gong, X. L., et al. (2013). A DNA methyltransferase inhibitor, 5-aza-2'-deoxycytidine, exacerbates neurotoxicity and upregulates Parkinson's disease-related genes in dopaminergic neurons. CNS Neurosci. Ther. 19, 183-190. doi: 10.1111/ cns.12059

Wasmuth, J. J., Hewitt, J., Smith, B., Allard, D., Haines, J. L., Skarecky, D., et al. (1988). A highly polymorphic locus very tightly linked to the Huntington's disease gene. Nature 332, 734-736. doi: 10.1038/332734a0

Wu, J., Basha, M. R., Brock, B., Cox, D. P., Cardozo-Pelaez, F., Mcpherson, C. A., et al. (2008). Alzheimer's disease (AD)-like pathology in aged monkeys after infantile exposure to environmental metal lead $(\mathrm{Pb})$ : evidence for a developmental origin and environmental link for AD. J. Neurosci. 28, 3-9. doi: 10.1523/JNEUROSCI.4405-07.2008

Yang, Y., Gozen, O., Vidensky, S., Robinson, M. B., and Rothstein, J. D. (2010). Epigenetic regulation of neuron-dependent induction of astroglial synaptic protein GLT1. Glia 58, 277-286. doi: 10.1002/glia.20922 
Yu, J., Tao, Q., Cheung, K. F., Jin, H., Poon, F. F., Wang, X., et al. (2008). Epigenetic identification of ubiquitin carboxyl-terminal hydrolase $\mathrm{L} 1$ as a functional tumor suppressor and biomarker for hepatocellular carcinoma and other digestive tumors. Hepatology 48, 508-518. doi: 10.1002/hep.22343

Yu, S., Li, X., Liu, G., Han, J., Zhang, C., Li, Y., et al. (2007). Extensive nuclear localization of alpha-synuclein in normal rat brain neurons revealed by a novel monoclonal antibody. Neuroscience 145, 539-555. doi: 10.1016/j.neuroscience.2006.12.028

Zajac, M. S., Pang, T. Y., Wong, N., Weinrich, B., Leang, L. S., Craig, J. M., et al. (2010). Wheel running and environmental enrichment differentially modify exon-specific BDNF expression in the hippocampus of wild-type and pre-motor symptomatic male and female Huntington's disease mice. Hippocampus 20, 621-636. doi: 10.1002/hipo.20658

Zhang, W., Tian, Z., Sha, S., Cheng, L. Y. L., Philipsen, S., and Tan-Un, K.-C. (2011). Functional and sequence analysis of human neuroglobin gene promoter region. $B B A$ 1809, 236-244. doi: 10.1016/j.bbagrm.2011.02.003
Conflict of Interest Statement: The authors declare that the research was conducted in the absence of any commercial or financial relationships that could be construed as a potential conflict of interest.

Received: 08 August 2013; accepted: 17 November 2013; published online: 05 December 2013.

Citation: Lu H, Liu X, Deng Y and Qing H (2013) DNA methylation, a hand behind neurodegenerative diseases. Front. Aging Neurosci. 5:85. doi: 10.3389/fnagi. 2013.00085

This article was submitted to the journal Frontiers in Aging Neuroscience.

Copyright (c) $2013 \mathrm{Lu}$, Liu, Deng and Qing. This is an open-access article distributed under the terms of the Creative Commons Attribution License (CC BY). The use, distribution or reproduction in other forums is permitted, provided the original author(s) or licensor are credited and that the original publication in this journal is cited, in accordance with accepted academic practice. No use, distribution or reproduction is permitted which does not comply with these terms. 